OPEN ACCESS

Edited by:

Kang-le Lu,

Jimei University, China

Reviewed by:

Patricia Diaz-Rosales,

Centro de Investigación en Sanidad Animal, CISA (INIA-CSIC), Spain

Seyyed Morteza Hoseini,

Iranian Fisheries Science Research Institute (IFSRI), Iran

${ }^{*}$ Correspondence:

Enric Gisbert

enric.gisbert@irta.cat

Eva Vallejos-Vidal

eva.vallejosv@usach.cl

tPresent address: Joana P. Firmino,

TECNOVIT-FARMFAES S.L., Alforja,

Spain

Specialty section:

This article was submitted to

Marine Fisheries, Aquaculture

and Living Resources,

a section of the journal

Frontiers in Marine Science

Received: 03 December 2021

Accepted: 04 January 2022

Published: 08 February 2022

Citation:

Salomón R, Furones MD, Reyes-López FE, Tort L, Firmino JP,

Quintela JC, Pinilla-Rosas JM, Vallejos-Vidal E and Gisbert E (2022) Phytogenics From Sage and Lemon Verbena Promote Growth, Systemic Immunity and Disease Resistance

in Atlantic Salmon (Salmo salar).

Front. Mar. Sci. 9:828497.

doi: 10.3389/fmars.2022.828497

\section{Phytogenics From Sage and Lemon Verbena Promote Growth, Systemic Immunity and Disease Resistance in Atlantic Salmon (Salmo salar)}

\author{
Ricardo Salomón 1,2, M. Dolors Furones ${ }^{1}$, Felipe E. Reyes-López ${ }^{3,4}$, Lluis Tort ${ }^{3}$, \\ Joana P. Firmino ${ }^{1 \dagger}$, José C. Quintela ${ }^{5}$, José M. Pinilla-Rosas ${ }^{5}$, Eva Vallejos-Vidal ${ }^{4,6 *}$ and \\ Enric Gisbert ${ }^{1 *}$
}

${ }^{1}$ IRTA, Centre de Sant Carles de la Ràpita (IRTA-SCR), Aquaculture Program, Sant Carles de la Ràpita, Spain, ${ }^{2}$ Ph.D. Program in Aquaculture, Universitat Autònoma de Barcelona, Bellaterra, Spain, ${ }^{3}$ Department of Cell Biology, Physiology and Immunology, Universitat Autònoma de Barcelona, Bellaterra, Spain, ${ }^{4}$ Centro de Biotecnología Acuícola, Facultad de Química y Biología, Universidad de Santiago de Chile, Santiago, Chile, ${ }^{5}$ Natac Biotech, Madrid, Spain, ${ }^{6}$ Facultad de Medicina Veterinaria y Agronomía, Universidad de Las Américas, Santiago, Chile

The transcriptomic response of the head kidney, the main lymphohematopoietic tissue of the body, was evaluated in Atlantic salmon (Salmo salar) smolts fed a functional feed containing a phytogenic rich in verbascoside and triterpenic compounds like ursolic acid. Fish (initial body weight $=55.0 \pm 0.1 \mathrm{~g}$ ) were fed two experimental diets $(40 \%$ crude protein, $22 \%$ crude fat; $21.6 \mathrm{MJ} / \mathrm{kg}$ gross energy) that only differed in the phytogenic content $(0.1 \%$ inclusion). Each diet has six replicates and was tested over a period of 133 days. The tested zootechnical feed additive a medicinal plant leaf extract (MPLE) obtained from sage (Salvia officinalis) and lemon verbena (Lippia citriodora). At the end of the trial, smolts fed the MPLE diet were heavier than their congeners from the control group ( $271.5 \pm 7.9 \mathrm{~g}$ vs. $240.2 \pm 19.3 \mathrm{~g}$, respectively; $P<0.05)$. Feed conversion ratio (FCR) values in fish fed the control diet were higher than those in fish fed the MPLE diet ( FCR $_{\text {controldiet }}=1.27 \pm 0.08$ vs. $F C_{0.1} \%$ MPLEdiet $\left.=1.08 \pm 0.05 ; P<0.05\right)$. The immunomodulatory properties of the functional diet were evaluated by means of an in vivo challenge with Aeromonas salmonicida subsp. salmonicida $\left(1 \times 10^{7} \mathrm{CFU}\right.$ $\mathrm{mL}^{-1}$ ). The microarray analysis of head kidney samples from both dietary groups revealed 1,178 differentially expressed genes (802 upregulated and 376 downregulated). Among them, several biological processes related to immunity were identified in fish fed the MPLE diet (i.e., interferon-gamma-mediated signaling pathway, antigen processing and presentation of peptide antigen via $\mathrm{MHC}$ class II, autophagy, regulation of i-kappaB kinase/NF-kappaB signaling, and leukocyte activation). Results from the bacterial challenge showed that survival rates were higher in smolts from the MPLE group $(90.6 \pm 6.4 \%)$ in comparison to the control group (60.7 $\pm 13.5 \%)$, confirming the functional benefits of the phytogenic in terms of host's immunity and disease resistance. Biological processes such as cytoskeleton organization and regulation of cellular protein metabolic process detected in fish fed the MPLE diet supported the metabolic changes related to increased somatic growth promoted. The present findings showed that the 
inclusion at $0.1 \%$ of the tested MPLE obtained from sage and lemon verbena in diets for Atlantic salmon smolts promoted somatic growth, and enhanced their systemic immune response and reduced mortality when fish were challenged with $A$. salmonicida cumulative, the causative agent of furunculosis in salmonids.

Keywords: feed additive, aquaculture, systemic immunity, Atlantic salmon, Aeromonas salmonicida, phytogenics

\section{INTRODUCTION}

Aquaculture is predicted to be the main source of aquatic dietary protein sources by 2050, playing a relevant role in food security and supply, as well as in poverty alleviation (Stentiford et al., 2020). The Atlantic salmon (Salmo salar) is the most important fish species consumed in the countries of the first world, whose production has strongly increased due to the development of this industry in the northern Europe and in North and South America, with Norway and Chile as the main world producers (FAO, 2021). Despite the sector's efforts focused on competitiveness and sustainable development to build this thriving sector, this rapid and continuous growth of the salmon farming has some side effects. In this sense, under intensive farming, fish can be influenced by various environment-related biotic and abiotic factors that can have potentially harmful or stressful effects (Taranger et al., 2015). All these factors have a negative impact on fish welfare and overall rearing performance, increasing susceptibility to disease; thus, negatively impacting the industry by causing health crises and economic losses (Tort, 2011; Taranger et al., 2015). This makes aquatic animal diseases one of the main factors limiting the growth of aquaculture and its sustainability (Reverter et al., 2020; Naylor et al., 2021).

Despite the fact that in 2022 several countries, including the EU, will ban the regular administration of antimicrobial agents in farming, including preventive group treatments (More, 2020), the general use of antibiotics for prophylactic purposes linked to intensive aquaculture activities can still be detected in some of the major aquaculture producing countries (Lulijwa et al., 2020; Schar et al., 2020). Thus, the need to develop health preventive treatments is becoming more of a necessity than an option. Thus, among the repertoire of tested strategies related to health management (Barrett et al., 2020; Miccoli et al., 2021), functional feeds are reputed as one of the most affordable solutions in terms of their prophylactic application. These diets are formulated for supporting the nutritional and physiological requirements of fish, as well as providing protection in front of biotic and abiotic stressors that are intrinsic to aquaculture rearing conditions (Waagbø and Remø, 2020). In this regard, the development and application of functional feeds represent a sound strategy for the aquaculture industry, as they provide functional benefits for animal health beyond their nutritional value, taking into account the purpose of their use either as nutritional, sensory, or functional additives (Vallejos-Vidal et al., 2016; Dawood et al., 2018). Thus, feed additives promoting immunity and enhancing stress and disease resistance in farmed fish have received notorious attention by the industry and academia as environmentally-friendly health management strategies. Therefore, phytogenics are among others, one of the most widely evaluated and recognized zootechnical feed additives with immunomodulatory properties (Encarnação, 2016). Phytogenics are defined as environmentally friendly plant-derived bioactive compounds that show positive effects on animal growth and health-promoting, antimicrobial, antiparasitic, immunostimulant, antioxidant, and antiinflammatory properties (Firmino et al., 2020; Dawood, 2021; Reverter et al., 2021).

Functional feeds based on phytogenics have been the focus of attention for the industry during the last decade due to their antimicrobial, immunostimulant, antioxidant, anti-stress, and growth-promoting functions (Awad and Awaad, 2017; Sutili et al., 2018; Hernández-Contreras and Hernández, 2020). Furthermore, phytogenics have shown to enhance both humoral and cellular immune response in teleosts (Elumalai et al., 2020; Firmino et al., 2021a,b), whereas other studies have also demonstrated their antimicrobial activity against a wide range of pathogenic organisms (Vaseeharan and Thaya, 2014; Firmino et al., 2021a). These functional properties make them very attractive for the industry as potential prophylactic dietary treatments. In particular, the current investigation endeavors to explore the dietary effects of phytogenics derived from a mixture of medicinal plants, the sage (Salvia officinalis, Lamiaceae) and the lemon verbena (Lippia citriodora, Verbenaceae), both recognized for their health and growth-promoting properties for aquatic species (Elumalai et al., 2020; Salomón et al., 2020, 2021a). In particular, in a previous study from our group, we showed that a medicinal plant leaf extract (MPLE) from sage and lemon verbena promoted an improvement in the classical key performance indicators (KPIs) linked to somatic growth and feed efficiency. These effects were coupled with a tightly controlled systemic immune response in an ex vivo assay using gilthead seabream (Sparus aurata) splenocytes stimulated by lipopolysaccharide (LPS; Salomón et al., 2020). In addition, we have recently reported that this MPLE obtained from sage and lemon verbena promoted gut integrity and immunity; particularly, $\mathrm{T}$ cell activation and differentiation (Salomón et al., 2021a).

In traditional medicine, S. officinalis has long enjoyed a reputation for its health benefits and for treating all kinds of ailments. Sage is a common herbal plant widely cultivated in various parts around the world, but it is native to the Mediterranean region. In addition, is known to be rich in phenolic compounds such as flavonoids, tannins, coumarins, and triterpenes (Ghorbani and Esmaeilizadeh, 2017), which are a highly diverse group of natural components widely found in a variety of common European plants and fruits (Vincken et al., 2007; Babalola and Shode, 2013). 
Thus, its content in functional compounds has attracted the attention within livestock and aquaculture industry. For instance, Simonová et al. (2010) reported that diets containing sage increased the energy content and amino acid profile in rabbit meat, in addition to promoting a good health condition of the animals. Similarly, Placha et al. (2015) demonstrated that sage promoted the integrity of the duodenal wall in laying hens. Regarding aquatic species, Sönmez et al. (2015) reported a positive effect of sage on growth performance and antioxidant enzyme activities in juvenile rainbow trout (Oncorhynchus mykiss). In this sense, several bioactive compounds have been identified in plants from the genus Salvia, such as flavonoids (Lu and Foo, 2000), phenolic acids (Wang et al., 1999), and pentacyclic triterpenes (Mašterová et al., 1989), among others. For instance, one of these triterpenic acids is ursolic acid, which is a pentacyclic terpenoid that has shown many beneficial properties effects on human health (Woźniak et al., 2015), and even in teleosts (Ding et al., 2015; Li et al., 2019). In zebrafish (Danio rerio), ursolic acid was reported to have antiinflammatory activity (Ding et al., 2015), whereas, in rainbow trout, a strong antiviral activity was reported both in vitro and in vivo (Li et al., 2019).

Lippia citriodora, colloquially known as lemon verbena, is a plant species of the Verbenaceae family that mostly grows in South America and is cultivated in northern Africa and southern Europe. Lemon verbena leaf extract contains polyphenols, including phenylpropanoids such as verbascoside, iridoids like gardoside, and flavonoids such as luteolin-7-diglucoronide, among which verbascoside acid is the most abundant compound in lemon verbena leaves, so most of its beneficial effects are attributed to this phytochemical (Sánchez-Marzo et al., 2019). Several studies have indicated that verbascoside acid is responsible for multiple beneficial properties of lemon verbena like its antioxidant (Mosca et al., 2014; Martino et al., 2016), anti-inflammatory, and antineoplastic properties in addition to numerous wound-healing and neuroprotective properties (Funes et al., 2009; Caturla et al., 2011; Alipieva et al., 2014). The use of lemon verbena in juvenile sheep has been reported to promote embryo development by protecting the oocyte against oxidative stress (Martino et al., 2016). In addition, another study showed that pigs fed with a diet enriched with verbascoside rich showed an improvement in their growth and feed efficiency performances (Corino et al., 2007; Pastorelli et al., 2012). Despite the existing literature, information on the function of these bioactive compounds of plant origin, such as sage and lemon verbena, is still scarce regarding their applications in animal production, especially their immunomodulatory effects on the systemic immune response and their potential use as a functional feed additive to promote disease resistance in fish.

Under this context, the present study aimed to evaluate the transcriptional responses of the head kidney in Atlantic salmon smolts fed a functional feed containing a mixture of MPLE obtained from sage and lemon verbena. At the end of the nutritional trial, disease resistance in smolts was evaluated by means of a bacterial challenge with the causative agent of furunculosis (Aeromonas salmonicida subsp. salmonicida).

\section{MATERIALS AND METHODS}

This study was divided into two different stages. Firstly, a nutritional trial during 133 days was conducted in order to evaluate the effects of the phytogenic on growth performance and transcriptomic analysis in head kidney of Atlantic salmon. The nutritional trial encompassed different periods, the parr phase (47 days; 19th December - 04th February); the smoltification phase, which started on the 5th of February and lasted 10 days; and the full seawater transfer stage that started on the 14th February until the end of the nutritional assay. In the second stage, fish from the nutritional trial were used in a bacterial challenge in order to test whether the tested MPLE diet provided protection to the host in front of a pathogenic bacteria responsible for furunculosis in salmonid fish.

\section{Diets}

Table 1 describes the ingredient list and proximate composition of the two experimental diets used in the current study. Diets were named as control and MPLE, and only differed in the level of inclusion of the MPLE obtained from S. officinalis and L. citriodora, which was $0.1 \%$ in the MPLE diet. The tested phytogenic was provided by NATAC Biotech SL and obtained as described in Salomón et al. (2020). The proximate composition of tested MPLE was: $73 \%$ carbohydrates, $2 \%$ crude lipids, $<1 \%$ crude proteins, $5 \%$ salts and $4 \%$ water. In terms of phytogenic bioactive compounds, the MPLE contained: 10\% ursolic acid

TABLE 1 | List of ingredients and proximal composition of experimental diets; control and a basal diet supplemented with MPLE tested in Atlantic salmon (Salmo salar).

\begin{tabular}{|c|c|c|}
\hline Ingredients, \% & Control diet & MPLE diet \\
\hline Fishmeal LT70 & 17.5 & 17.5 \\
\hline Soy protein concentrate & 20.0 & 20.0 \\
\hline Fish protein concentrate & 2.5 & 2.5 \\
\hline Wheat gluten & 9.0 & 9.0 \\
\hline Corn gluten & 5.0 & 5.0 \\
\hline Faba beans & 5.0 & 5.0 \\
\hline Wheat meal & 16.23 & 16.13 \\
\hline Fish oil & 12.0 & 12.0 \\
\hline Vitamin and mineral premix & 1.0 & 1.0 \\
\hline Soy lecithin & 0.5 & 0.5 \\
\hline Vitamin C35\% & 0.07 & 0.07 \\
\hline Monocalcium phosphate & 3.0 & 3.0 \\
\hline Rapeseed oil & 7.0 & 7.0 \\
\hline Betaine $\mathrm{HCl}$ & 1.0 & 1.0 \\
\hline DL-Methionine & 0.2 & 0.2 \\
\hline MPLE & - & 0.10 \\
\hline \multicolumn{3}{|l|}{ Proximate composition } \\
\hline Crude protein, \% & 40.03 & 40.02 \\
\hline Crude fat, \% & 22.15 & 22.15 \\
\hline Fiber, \% & 1.75 & 1.74 \\
\hline Starch, \% & 13.02 & 12.93 \\
\hline Ash, \% & 8.74 & 8.89 \\
\hline Gross energy, MJ/kg & 21.60 & 21.58 \\
\hline
\end{tabular}


(100 ppm), 3\% other triterpenic compounds (30 ppm), 2\% verbascoside $(60 \mathrm{ppm})$ and $<1 \%$ polyphenols $(<10 \mathrm{ppm})$. Diets were manufactured by Sparos Lda (Olhão, Portugal). All powder ingredients were mixed accordingly to the target formulation in a double-helix mixer (model 500L, TGC Extrusion, France) and ground (below $400 \mu \mathrm{m}$ ) in a micropulverizer hammer mill (model SH1, Hosokawa-Alpine, Germany). Diets (pellet size: 2 and $3 \mathrm{~mm}$ ) were manufactured with a twin-screw extruder (model BC45, Clextral, France) with a screw diameter of $55.5 \mathrm{~mm}$. Extrusion conditions: feeder rate $(80-85 \mathrm{~kg} / \mathrm{h})$, screw speed (247-266 rpm), water addition in barrel $1(345 \mathrm{ml} / \mathrm{min})$, temperature barrel $1\left(32-34^{\circ} \mathrm{C}\right)$, temperature in barrel 2 (59$62)$, and temperature barrel $3\left(111-114^{\circ} \mathrm{C}\right)$. Extruded pellets were dried in a vibrating fluid bed dryer (model DR100, TGC Extrusion, France). After cooling, oils were added by vacuum coating (model PG-10VCLAB, Dinnissen, Netherlands). Coating conditions were: pressure (700 mbar); spraying time under vacuum (approximately $90 \mathrm{~s}$ ), return to atmospheric pressure (120 s). Feeds were stored at $4^{\circ} \mathrm{C}$ during the experimental period (133 days) in order to prevent their oxidation.

\section{Fish and Experimental Design}

Unvaccinated Atlantic salmon parrs $(n=1,550)$ were purchased from SARL SALMO (Gonneville-Le Thiel, France) and transported by road to IRTA-Sant Carles de la Ràpita research facilities (Sant Carles de la Ràpita, Spain). Once there, parrs were acclimated in two 2,000-L tanks connected to an open-flow system $\left(12.0 \pm 1.5^{\circ} \mathrm{C}\right)$ for 2 weeks under natural photoperiod and fed ad libitum a commercial feed (T2-2 Royal Optime, Skretting; proximate composition: $44 \%$ crude protein; $21 \%$ crude fat; $6.9 \%$ crude ash; $2.9 \%$ crude fiber).

Before the onset of the nutritional trial, parrs $(n=696)$ were gently anesthetized ( $50 \mathrm{mg} \mathrm{L}^{-1}$ tricaine methane sulfonate. MS222, Sigma-Aldrich, Madrid, Spain) and individually measured in body weight (BW) and standard length (SL) to the nearest $0.1 \mathrm{~g}$ and $1 \mathrm{~mm}$, respectively. Fish $(55.0 \pm 0.1 \mathrm{~g}$ and $16.2 \pm 0.2 \mathrm{~mm}$ in BW and SL, respectively) were distributed among twelve experimental tanks $(n=58$ fish per tank; 6 replicate tanks per experimental diet). Both experimental diets were offered to parrs at a daily feeding rate of $3.0 \%$ of the stocked biomass as described in Salomón et al. (2021b). In addition, feed utilization was evaluated by the following formula: feed conversion ratio $(F C R)=$ feed intake $(\mathrm{g}) /$ increase of fish biomass $(\mathrm{g})$.

During the parr phase that lasted 47 days, rearing conditions were as follows: water temperature and $\mathrm{pH}$ ( $\mathrm{pH}$ meter 507; Crison Instruments, Barcelona, Spain), salinity (MASTER-20T; ATAGO Co., Ltd., Tokyo, Japan), and dissolved oxygen (OXI330; Crison Instruments) were $12.2 \pm 1.0^{\circ} \mathrm{C}, 7.4 \pm 0.3$ and $9.4 \pm 0.8 \mathrm{mg} \mathrm{L}^{-1}$ (mean $\pm \mathrm{SD}$ ), respectively. The water flow rate in experimental tanks was maintained at approximately $9.0 \mathrm{~L} \mathrm{~min}^{-1}$ (open-flow system), which guaranteed two full tank's water renewal per hour. Photoperiod was $8 \mathrm{~h}$ light: $16 \mathrm{~h}$ darkness.

Smoltification started on the 5th of February and lasted 10 days. During this period, water salinity was increased progressively at $c a .3 \mathrm{ppt}$ per day until reaching $35 \mathrm{ppt}$ using filtered seawater according to SARL SALMO recommendations. Water temperature, $\mathrm{pH}$, and oxygen levels during this period were $12 \pm 0.1^{\circ} \mathrm{C}, 7.4 \pm 0.3$ and $9.6 \pm 0.2 \mathrm{mg} \mathrm{L}^{-1}$. The photoperiod during the smoltification period was $24 \mathrm{~h}$ light, $0 \mathrm{~h}$ darkness. Once fish were transferred to seawater 14th February, water quality and temperature were maintained by means of a water recirculation system (IRTAmar ${ }^{\circledR}$; Spain) that maintained adequate water quality through UV, biological, and mechanical filtration. Water quality parameters during the rest of the trial were $12.1 \pm 0.2^{\circ} \mathrm{C}, 7.4 \pm 0.3$ and $9.5 \pm 0.2 \mathrm{mg}$ $\mathrm{L}^{-1}$. Ammonia and nitrite were $\leq 0.07$ and $0.14 \mathrm{mg} \mathrm{L}^{-1}$, respectively. Ammonia and nitrites were measured twice per week by means of a portable spectrophotometer (LOVIBOND MD600, Tintometer GmbH, Germany) using the Vario Ammonia Salicyklate F $10 \mathrm{~mL}$ (Tintometer GmbH, Germany) and Nitriver ${ }^{\circledR}$ 3 Nitrite reagent (Permachem ${ }^{\circledR}$ Reagent, HACH Lange, GmbH) assays. The photoperiod during the smolt stage was $24 \mathrm{~h}$ light: $0 \mathrm{~h}$ darkness. The illumination system for the smolt phase consisted of a led illumination system (Celer, Spain) with a light temperature of $4.000 \mathrm{~K}$ and light intensity of 1.540 lumens. At the end of the trial, all fish were netted, anesthetized with MS-222 as previously described and individually weighted.

\section{Pathogenic Bacterial Challenge}

At the end of the nutritional trial, smolts fed both diets were exposed to a bacterial challenge with the causative agent of furunculosis (A. salmonicida subsp. salmonicida). The internal coding for this pathogenic bacterial strain is IRTA-17-44, a strain available for courtesy of HIPRA (Amer, Spain). In brief, the bacterial inoculum was grown on TSA at $23.0 \pm 1.0^{\circ} \mathrm{C}$ for $48 \mathrm{~h}$. The inoculum was prepared to an optical density $(\mathrm{OD})=1.2$ measured at $\lambda=550 \mathrm{~nm}$, which corresponded to $1 \times 10^{8} \mathrm{CFU}$ $\mathrm{mL}^{-1}$. The bacterial suspension was ten-fold serially diluted in sterile PBS to prepare the desired inoculum density, which was confirmed by CFU's plate counting. Prior to the challenge trial, the lethal dose of $50 \%\left(\mathrm{LD}_{50}\right)$ for $A$. salmonicida was determined for the experimental conditions established. For this purpose, thirty smolts ( $n=10$ per dose) were intraperitoneally injected $(0.2 \mathrm{~mL})$ at three different concentrations of the pathogenic

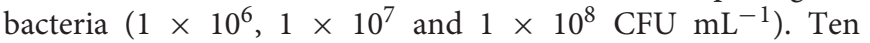
additional fish were injected with PBS as methodological control.

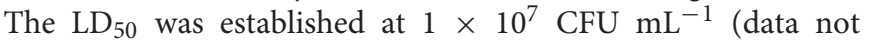
shown). For the challenge trial, 32 Atlantic salmon smolts $(\mathrm{BW}=194.0 \pm 29.1 \mathrm{~g})$ per each dietary treatment were randomly distributed $^{1}$ into quadruplicate tanks (4 tanks per dietary treatment), with eight fish per tank (stocking density $=14-$ $16 \mathrm{~kg} \mathrm{~m}^{-3}$ ). During the acclimation period (5 days), fish were fed ad libitum with the same experimental diets used in the nutritional assay. After acclimation, fish were anesthetized and IP injected with $0.2 \mathrm{~mL}$ of $10^{7} \mathrm{CFU} / \mathrm{mL}$ of $A$. salmonicida (IRTA17-44).

Both the establishment of the A. salmonicida $\mathrm{LD}_{50}$ and the challenge trial were performed at IRTA's biosafety challenge room, in 32 cylindrical tanks (100 L) connected to a RAS unit (IRTAmar ${ }^{\circledR}$ ) equipped with real-time control of oxygen and temperature, mechanical filtration, biofiltration, and ultraviolet disinfection of the water. The outflow water was chlorinated,

\footnotetext{
${ }^{1}$ https://www.randomizer.org
} 
followed by ozone treatment before being discharged. Water quality conditions in terms of temperature and salinity were $13.1 \pm 1.1^{\circ} \mathrm{C}$ and $32.3 \pm 0.4 \mathrm{ppt}$, respectively. Mortality occurring after the first $12 \mathrm{~h}$ post-injection (hpi) was considered to be induced A. salmonicida rather than handling stress, since no mortality was found in the control group injected with PBS.

During the duration of the challenge (12 days), smolts were supervised every $2 \mathrm{~h}$, six times per day, including weekends. Following the ethical guidelines for the use of animals in research, when fish became moribund, they were euthanized with an overdose of MS-222 (>150 $\left.\mathrm{mg} \mathrm{L}^{-1}\right)$. At the end of the challenge, all fish were sacrificed following the same procedure. A speciesspecific PCR (Beaz-Hidalgo et al., 2008) was performed from DNA of bacterial colonies recovered from head kidney smears of all moribund fish in order to confirm the cause of death. For this purpose, animals were aseptically dissected and a sample from the head kidney was taken and plated on TSA, incubated at $23^{\circ} \mathrm{C}$ for $72 \mathrm{~h}$. Confluent pure bacterial growth was found from all samples, from which A. salmonicida was confirmed by means of PCR as described in Salomón et al. (2021b).

\section{Transcriptional Analysis \\ RNA Isolation and Quality Control}

At the end of the nutritional assay, three fish from each tank ( $n=18$ fish per diet) were sacrificed with an overdose of MS222 (>150 $\mathrm{mg} \mathrm{L}^{-1}$ ). Then, head kidney was removed and fixed in RNAlater ${ }^{\circledR}$ (Sigma-Aldrich, Sant Louis, MO, United States), incubated overnight $\left(4^{\circ} \mathrm{C}\right)$, and stored at $-80^{\circ} \mathrm{C}$. Total RNA from the head kidney of individual fish was extracted using TRI reagent (Sigma-Aldrich, Sant Louis, MO, United States) following the guidelines provided by the manufacturer. Total RNA concentration and purity were quantified using a Nanodrop$2000^{\circledR}$ spectrophotometer (Thermo Scientific ${ }^{\mathrm{TM}}$, United States) and stored at $-80^{\circ} \mathrm{C}$ for further analysis. To check RNA integrity, samples were diluted (133.33 $\left.\mathrm{ng} \mu \mathrm{L}^{-1}\right)$ and the RNA Integrity Number (RIN) determined by means of an Agilent 2100 Bioanalyzer (Agilent Technologies, Spain). Only samples with a RIN value higher than 8.5 were selected for further microarray analysis. For each dietary group, we used for microarray analysis three head kidney pooled samples. Each pool consisted of one fish from each tank replicate ( $n=18$ fish per dietary group); thus, data regarding individual variability was lost with this analysis.

\section{Microarray Design and Analysis}

Gene expression analysis from head kidney samples was performed using the custom-commercial Salmo salar oligonucleotide microarray platform (AMADID 084881; Gene Expression Omnibus (GEO) access number: GPL28080; Agilent Technologies, United States). Data from this study are available in the GEO accession number GSE184485.

RNA handling and the microarray analysis of samples were conducted as described by Salomón et al. (2021b). Total RNA (200 ng) was reverse transcribed (Agilent OneColor RNA spike-in kit; Agilent Technologies) and used as a template for Cyanine-3 (Cy3) labeled cRNA synthesis and amplification (Quick Amp Labeling kit, Agilent Technologies). The RNeasy micro kit (Qiagen) was used for cRNA purification.
Dye incorporation and cRNA yield were checked with the NanoDrop ND-2000 ${ }^{\circledR}$ spectrophotometer. Then, Cy3-labeled cRNA ( $1.5 \mathrm{mg}$ ) with specific activity $>6.0 \mathrm{pmol}$ Cy3/mg cRNA was fragmented $\left(60^{\circ} \mathrm{C}, 30 \mathrm{~min}\right)$, and then mixed with the hybridization buffer and hybridized to the array (ID 084881, Agilent Technologies) at $65^{\circ} \mathrm{C}$ for $17 \mathrm{~h}$ (Gene expression hybridization kit; Agilent Technologies). The microarray was washed as indicated by the manufacturer (Gene expression wash buffers; Agilent Technologies), followed by the application of stabilizing and drying solutions (Agilent Technologies). Microarray slides were scanned (Agilent Technologies Scanner, model G2505B) and spot intensities and other quality control features were extracted with Agilent's Feature Extraction software version 10.4.0.0 (Agilent Technologies). Quality reports were checked for each array. The identification of differentially expressed genes was done as described by Reyes-López et al. (2015). Data processing and mining were performed by means of the package STARS (NOFIMA, Norway) (Krasnov et al., 2011). Lowess normalization of $\log 2$-expression ratios (ER) was performed after removing the low-quality spots formerly identified. The selection of differentially expressed genes (DEGs) was done considering the difference between both diets following an unpaired $t$-test $(P<0.05)$.

\section{Functional Network Analyses: Transcripteractomes}

The transcripteractome analysis was conducted according to Reyes-López et al. (2021) using the Search Tool for the Retrieval of Interacting Genes (STRING) public repository version $10.0^{2}$ (Szklarczyk et al., 2019). A protein-protein interaction (PPI) network for DEGs was done with a high-confidence interaction score (value $=0.4$ ). The mechanisms of response in which DEGs are involved were obtained from a comparative analysis using Homo sapiens as a reference organism. Thus, an $H$. sapiens acronym was assigned based on S. salar transcript annotation using Uniprot (2019) and Genecards (Stelzer et al., 2016) databases. When genes with no annotation match were found for Atlantic salmon, we assigned an orthologue H. sapiens Entrez Gene based on the homology between sequences using the best tBlastX (NCBI) hit. Matches with at least $E$ value $\leq 1 \mathrm{e}^{-10}$ were only considered, whereas the Uniprot and Genecards databases were used to confirm the match of the gene acronym tag between both species. Gene ontology (GO) pathway enrichment analysis for biological processes (GO_BiologicalProcess-EBIUniProt-GOA-ACAP-ARAP_10.11.2020_00h00) was obtained using ClueGO v2.5.7 (Bindea et al., 2009) through Citoscape 3.8.2 (Shannon et al., 2003). The enrichment and depletion of GO categories (two-sided hypergeometric test; $P<0.05$ ) using the Benjamini-Hochberg correction. Furthermore, a GO Fusion was run in order to avoid redundant terms with a Kappa Score Threshold of 0.4 in order to propose more stringent GO terms associated to the mechanism of response for the MPLE diet. GO terms grouping was performed when the sharing group's percentage was above $50(P<0.05)$. The statistically significant GOs obtained from the enrichment analysis were assigned to each one of the nodes represented in the functional

\footnotetext{
${ }^{2}$ https://string-db.org
} 
network. The ClueGo v2.5.7 a Cytoscape plug-in was used for visualizing nodes classified in different clusters based on their functionality. Hub genes of PPI networks were calculated by Cytoscape plug-in, cytoHubba (version 0.1), predicted the top 10 nodes using analysis algorithms including Maximum Clique Centrality (MCC; Chin et al., 2014).

\section{Ethics Statement}

Experimental procedures were conducted following the Guiding Principles for Biomedical Research Involving Animals (EU2010/63) and the guidelines of the Spanish laws (law 32/2007 and RD 1201/2015) and authorized by the Ethical Committee of IRTA (FUE-2020-01314717).

\section{Statistics}

Data in terms of somatic growth performance was compared between the control and the MPLE diets by means of a $t$-test $(P<0.05)$. Regarding the bacterial challenge, mortality rates were registered in both groups and data were depicted using Kaplan-Meier survival curves (Kaplan and Meier, 1958). Survival rates were calculated using the Mantel-Cox log-rank test. All the statistical analyses were conducted using SPSS for Windows ${ }^{\circledR}$ (version 15.0, SPSS Inc., Chicago, IL, United States). The Heatmapper server was used for constructing the hierarchical heatmap of DEGs (Babicki et al., 2016).

\section{RESULTS}

\section{Survival and Growth Performance}

At the end of the study, no significant differences in survival were found between Atlantic salmon smolts fed the control $(98.9 \pm 1.9 \%)$ and MPLE $(99.4 \pm 1.3 \%)$ diets $(P>0.05)$. Smolts fed the MPLE diet $(271.5 \pm 7.9 \mathrm{~g})$ were $11.5 \%$ heavier than those fed the control diet $(240.2 \pm 19.3 \mathrm{~g})(P<0.05)$. Values of FCR were lower in fish fed the $0.1 \%$ MPLE diet $(1.08 \pm 0.05)$ than in those fed the control diet $(1.27 \pm 0.08)(P<0.05)$.

\section{Head Kidney Transcriptomic Results}

A total of 1,178 DEGs were found in the head kidney of smolts fed the MPLE diet compared to the control group (Figure 1). The complete list of DEGs may be found in Supplementary Table 1. Most of the upregulated genes $(n=523)$ were found within the $0.8<\log 2$ absolute fold-change $(|\log 2 \mathrm{FC}|)<1.4$ interval. In addition, 243 genes were identified in the $1.4<|\log 2 \mathrm{FC}|$ $<2.5$ interval, 35 transcripts in the $2.5<|\log 2 \mathrm{FC}|<5.0$, and only one single gene in the $|\log 2 \mathrm{FC}|>5.0$. Regarding downregulated genes, 289 transcripts were found in the $0.8<1$ $\log 2 \mathrm{FC} \mid<1.4$ interval; other 76 transcripts were grouped in the $1.4<|\log 2 \mathrm{FC}|<2.5$ interval, whereas only 11 DEGs were included in the $2.5<|\log 2 \mathrm{FC}|<5.0$ expression interval. The detailed analysis of gene absolute log2 fold-change (| log2 FC|) revealed that genes were mostly upregulated in fish fed the MPLE diet ( $68.1 \%$ of DEGs), while its gene modulation was moderate in terms of FC intensity (Figure 1A). Results from the PCA are shown in Figure 1B, whereas those related to the hierarchical clustering heatmap of DGEs from both diets are depicted in Figure 1C.

\section{Enrichment Analyses and Transcripteractome Results}

The analysis of the transcripteractome showed the presence of thirty-four clusters (Table 2). The complete list of them is detailed in Supplementary Table 2. Among them, eleven clusters were identified with only one-single node, four clusters were constituted by two nodes, four clusters by three nodes, and four clusters by four nodes (Figure 2). Only one cluster was identified composed by five (GO:0042770: "signal transduction in response to DNA damage"), six (GO:0007492: "endoderm development"), seven (GO:0071901: "negative regulation of protein serine/threonine kinase activity"), and nine nodes (GO:0043122: "regulation of I-kappaB kinase/NF-kappaB signaling"). Other seven clusters contained more than ten nodes, including the "activation of cysteine-type endopeptidase activity involved in apoptotic process" (GO:0006919; eleven nodes), "response to organonitrogen compound" (GO:0010243; eleven nodes), "leukocyte activation involved in immune response" (GO:0002366; thirteen nodes), "intracellular signal transduction" (GO:0035556; thirteen nodes), “Autophagy" (GO:0006914; sixteen nodes). Importantly, two clusters registered more than thirty nodes including the "regulation of DNA-binding transcription factor activity” (GO:0051090; thirty-seven nodes), and the "actin filament organization" (GO:0007015; forty-one nodes) (Figure 2).

Through plugin cytoHubba in Cytoscape software, we evaluated the degree and betweenness centrality in the PPI network and screening the hub genes. Thus, the top ten hub genes with a high level of correlation for the selected clusters related to immunity and obtained from the enriched biological functions were selected for further consideration. From the "Antigen processing and presentation of peptide antigen via MHC class II", we identified six upregulated transcripts (hladqa1, cd74, ctsl, ctsd, kif23, dync1li2) and four downregulated hub genes (klc1, hla-dmb, kif2a, sptbn2) (Figure 3A). Considering the cluster "Interferon-gamma-mediated signaling pathway", among the top 10 hub genes, six transcripts were upregulated

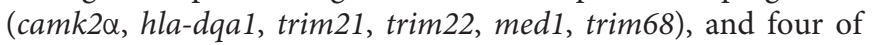
them downregulated (jak1, jak2, tp53bp1, ncam1) (Figure 3B). For the cluster "Regulation of I-kappaB kinase/NF-kappaB signaling”, we identified five upregulated transcripts (notch1, cebpb, smad3, sirt1, cd40), and five others were downregulated (gapdh, jak2, spi1, smad4, brd4) (Figure 3C). Considering the cluster "Leucocyte activation involved in immune response", most of the hub genes were upregulated ( $f n 1$, notch1, grb2, rac2, $r d x, e z r, s m a d 3, a b l 1)$ compared to the two downregulated hub genes ( $a c t b, j a k 2$ ) (Figure 3D). Regarding the cluster "Cytoskeleton organization", seven hub genes were upregulated (fn1, notch1, itgb4, itgb5, itga11, col2a1, col4a5), and three downregulated (actb, gapdh, itga10) (Figure 3E). Considering the cluster "Regulation of cellular protein metabolic process", just three genes were upregulated ( $f n 1, i r s 1$, sirt1), whereas seven genes showed a downregulation ( $a c t b$, gapdh, jak2, ptpn1, 
A

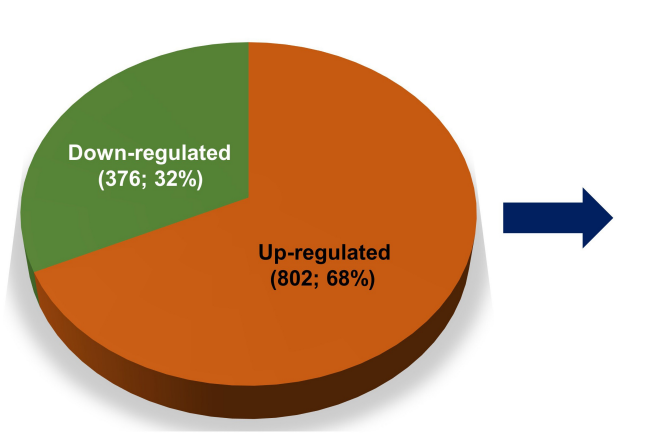

B

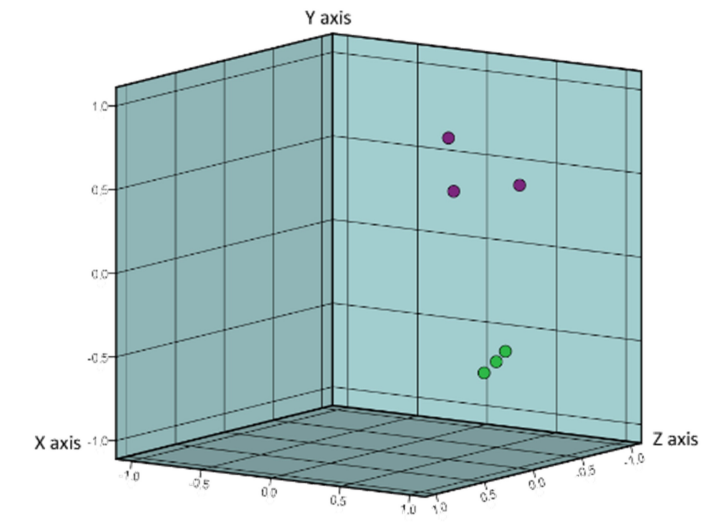

C

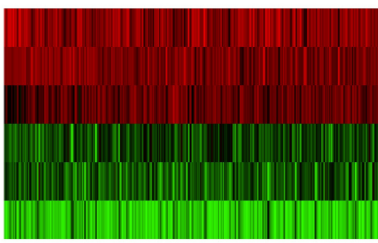

Color range

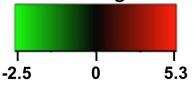

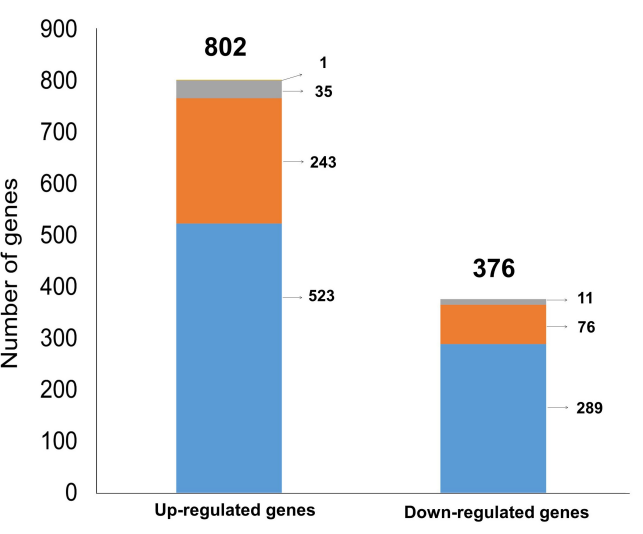

$=|\log 2 \mathrm{FC}|>5.0$

$-2.5<|\log 2 \mathrm{FC}|<5.0$

$-1.4<|\log 2 \mathrm{FC}|<2.5$

$=0.8<|\log 2 \mathrm{FC}|<1.4$

FIGURE 1 | Differential expression analysis of the Atlantic salmon (S. salar) head kidney transcriptomic response to MPLE diet. (A) Distribution (pie-chart) of the differential expressed genes (DEGs) obtained from the microarray-based transcriptomic analysis response fed a diet supplemented with phytochemicals from sage and lemon verbena. Absolute log2 fold-change (log2 FC) indicates the magnitude interval of response. (B) Principal component analysis (PCA) of the DEGs for the Atlantic salmon head kidney in response to the control (purple node) and phytogenic-supplemented diet (green node). (C) Hierarchical clustering of the Atlantic salmon head kidney transcriptomic response for the control and MPLE diet, based on similitude patterns of the DEGs detected from three sample pools per dietary group. Data of the six microarrays are depicted. The normalized intensity values (log2) obtained for each microarray analyzed for control (replicate 1, 2, and 3) and MPLE group (replicate 1, 2, and 3) are shown.

jak1, smad4, insr) (Figure 3F). The "Cellular biosynthetic process" cluster showed also ten hub genes. From them, seven genes were upregulated ( $r p s 6, r p l 19, r p l 26, r p l 12, r p s 7, r p s 17$, dock4), and three of them were downregulated (rps10, rpl3l, eef1d) (Figure 3G). For the GO "Autophagy," five genes were upregulated (sirt1, prkaa2, slc38a9, trim21, abl1), and other five genes were downregulated (gapdh, ube2v1, ube2n, tp53bp1, $g b a)$ (Figure 3H).

\section{Bacterial Challenge Test}

Results regarding the Kaplan-Meier survival rates curves of Atlantic salmon smolts injected intraperitoneally with $A$. salmonicida $\left(1 \times 10^{7}\right.$ UFC $\left.\mathrm{mL}^{-1}\right)$ showed significant differences between the control and MPLE diets (Figure 4; $P<0.05$ ). Smolts fed the MPLE diet showed higher survival rates $(90.6 \pm 6.4 \%$, mean \pm standard deviation) compared to those smolts fed the control diet $(60.7 \pm 13.5 \%)$.

\section{DISCUSSION}

Nowadays, transcriptome-based functional network analyses on teleost fish fed functional feeds have gained attention, since they provide further insight into the mode of action 
TABLE 2 | List of the 34 total clusters related to representative biological processes identified by the transcripteractome in Atlantic salmon smolts fed the MPLE diet.

\begin{tabular}{|c|c|c|c|c|}
\hline & Cluster term & $\%$ Terms per group & No. GO & No. Genes \\
\hline ○ & Actin cytoskeleton organization & 18.98 & 41 & 300 \\
\hline ○ & Cellular biosynthetic process & 17.13 & 37 & 556 \\
\hline ○ & Autophagy & 7.41 & 16 & 230 \\
\hline ○ & Regulation of cellular metabolic process & 6.02 & 13 & 407 \\
\hline ○ & Leukocyte activation involved in immune response & 6.02 & 13 & 171 \\
\hline 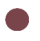 & Response to organic substance & 5.09 & 11 & 184 \\
\hline O & Activation of cysteine-type endopeptidase activity involved in apoptotic process & 5.09 & 11 & 155 \\
\hline - & Regulation of I-kappaB kinase/NF-kappaB signaling & 4.17 & 9 & 130 \\
\hline - & Negative regulation of protein serine/threonine kinase activity & 3.24 & 7 & 178 \\
\hline ○ & Endoderm development & 2.78 & 6 & 49 \\
\hline ○ & Signal transduction in response to DNA damage & 2.31 & 5 & 38 \\
\hline ○ & Intracellular signal transduction & 1.85 & 4 & 215 \\
\hline ○ & Regulation of histone methylation & 1.85 & 4 & 32 \\
\hline ○ & Cytoskeleton organization & 1.85 & 4 & 307 \\
\hline O & Regulation of intracellular steroid hormone receptor signaling pathway & 1.85 & 4 & 79 \\
\hline ? & Regulation of viral life cycle & 1.39 & 3 & 24 \\
\hline ○ & Positive regulation of cell death & 1.39 & 3 & 93 \\
\hline O & Regulation of cellular protein metabolic process & 1.39 & 3 & 373 \\
\hline ○ & Positive regulation of neuron death & 1.39 & 3 & 26 \\
\hline ○ & Sphingolipid metabolic process & 0.93 & 2 & 18 \\
\hline O & Regulation of cellular protein localization & 0.93 & 2 & 40 \\
\hline O & Carbohydrate derivative metabolic process & 0.93 & 2 & 50 \\
\hline ○ & Chondrocyte differentiation & 0.93 & 2 & 21 \\
\hline - & Protein localization to nucleus & 0.46 & 1 & 22 \\
\hline O & Maintenance of protein location & 0.46 & 1 & 11 \\
\hline C & Actin cytoskeleton reorganization & 0.46 & 1 & 11 \\
\hline ○ & Regulation of cell shape & 0.46 & 1 & 14 \\
\hline O & Nuclear-transcribed mRNA catabolic process, nonsense-mediated decay & 0.46 & 1 & 12 \\
\hline O & Antigen processing and presentation of peptide antigen via MHC class II & 0.46 & 1 & 11 \\
\hline C & Cell-cell adhesion & 0.46 & 1 & 56 \\
\hline ○ & Hepaticobiliary system development & 0.46 & 1 & 15 \\
\hline O & Stem cell differentiation & 0.46 & 1 & 21 \\
\hline - & Interferon-gamma-mediated signaling pathway & 0.46 & 1 & 10 \\
\hline ○ & Negative regulation of transcription by RNA polymerase ॥ & 0.46 & 1 & 52 \\
\hline
\end{tabular}

of zootechnical additives with immunomodulatory properties on the host (Firmino et al., 2021a; Reyes-López et al., 2021; Salomón et al., 2021a,b). In this sense, this study was performed to gain insight into the potential immunomodulatory, disease resistance, and other biological effects of a phytogenic feed additive obtained from sage and lemon verbena in Atlantic salmon smolts. These bioactive compounds were chosen due to their health and growth-promoting properties in aquatic species (Elumalai et al., 2020; Salomón et al., 2020, 2021a) and screened as a potential additive for a functional feed in order to promote host's immunity and enhance disease resistance. In this context, we found that the inclusion of MPLE at $0.1 \%$ in Atlantic salmon smolts exerted a positive effect on somatic growth, being fish fed the diet containing the MPLE $11.5 \%$ heavier than the control group. Similar results have been observed in higher vertebrates (Corino et al., 2007; Pastorelli et al., 2012; Casamassima et al., 2013) and in fish species like gilthead sea bream fed the same feed additive (Salomón et al., 2020) and other species like rainbow trout or beluga fed functional diets containing sage and/or lemon verbena phytogenics (Sönmez et al., 2015; Dadras et al., 2020). These findings might be partially attributed to the potential effects of triterpenoid compounds, such the ursolic acid, which has been reported to promote muscular growth by the hypertrophy of muscular fibers in mice (Kunkel et al., 2012) and rainbow trout (Fernández-Navarro et al., 2006). Furthermore, the growth-promoting effects of polyphenolic compounds like verbascoside present in $L$. citriodora have also been observed in several studies (Corino et al., 2007; Pastorelli et al., 2012; Casamassima et al., 2013).

\section{Regulation of Cellular Protein Metabolic and Cytoskeleton Organization}

The transcripteractome results showed the enrichment of the biological processes related to "Regulation of cellular protein metabolic process (GO:0031323)", "Positive regulation 


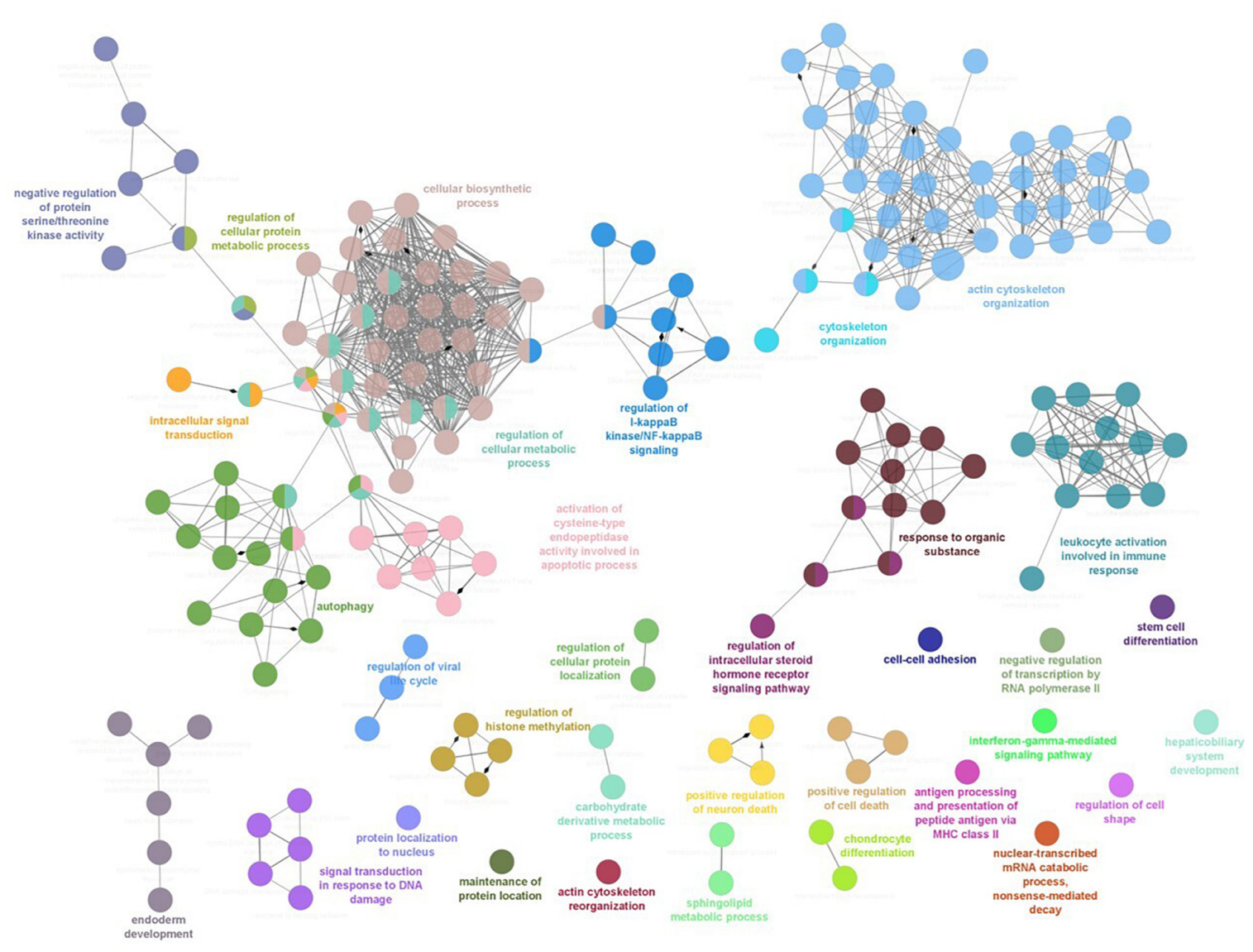

FIGURE 2 | Functional enrichment network analysis for biological processes based on the total number of differential expressed genes (DEGs) in head kidney of Atlantic salmon smolts fed the MPLE-supplemented diet. Each node represents a specific enriched biological process from the total number of DEGs. Each color indicates a cluster of closely related biological processes. The lines into the cluster indicated a closed relationship between biological processes. The details of each node are shown in Supplementary Table 2.

of metabolic process (GO:0009893)", and "Regulation of catabolic process (GO:0009894)". The identification of the abovementioned biological processes in the head kidney of smolts fed the functional diet may be attributed to their higher somatic growth performance, which in turn may increase the metabolism of the body, and in particular, that of this lymphoid tissue (Shved et al., 2011; Khansari et al., 2017), as different gene expression patterns between both dietary groups indicated. For instance, among several hub genes identified by the cytoHubba analysis tool (Chin et al., 2014), sirt1 was one of the hub genes that showed upregulation in the cluster named "Regulation of cellular protein metabolic". In mammals, its protein product (Sirtuin 1) play a vital role in metabolism as a mediator of endocrine function of several hormones modulating energy balance (Quiñones et al., 2014). Thus, our results are also in accordance with those of Lagouge et al. (2006) and Milne et al. (2007), who reported an upregulation of sirt1 due to the dietary administration of resveratrol, a natural polyphenol found in several plants; results that confirmed the role of sirtuin 1 as key regulator of energy and metabolic homeostasis. Other hub genes related to "Regulation of cellular protein metabolic" process were the insulin receptor substrate 1 (irs1) and insulin receptor (insr), both transcripts were upregulated in the head kidney of smolts fed the MPLE diet. Their protein products are known as insulin receptor substrates, which are mediators of insulin signaling, and have a significant role in maintaining growth and metabolic cell functions (Caruso and Sheridan, 2011; Shved et al., 2011). This is relevant since insulin plays a fundamental role in the regulation of somatic growth and metabolism of all vertebrates (Hernández-Sánchez et al., 2006). Thus, the upregulation of genes associated to insulin receptors reinforces the hypothesis of a growth-promoting effect of the tested MPLE in Atlantic salmon smolts.

The cytoskeleton is the cellular structure that helps cells maintain their shape and internal organization; in particular, it spatially organizes the contents of the cell; it connects the cell physically and biochemically to the external environment; and it generates coordinated forces that enable the cell to move and change shape while providing cellular homeostasis and survival (Fletcher and Mullins, 2010). In this sense, we found the modulation of transcripts associated to the biological process "Cytoskeleton organization (GO:0007010)". Interestingly, several genes related to cell structure and morphogenesis (extracellular 


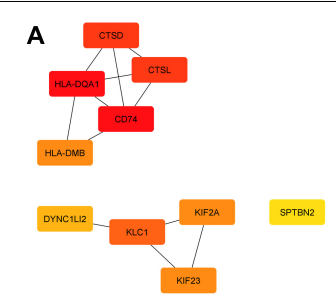

E

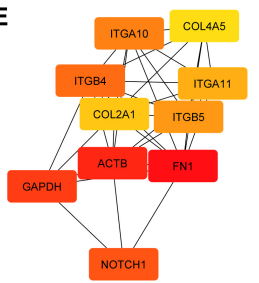

B

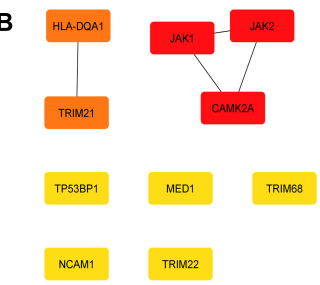

$\mathbf{F}$

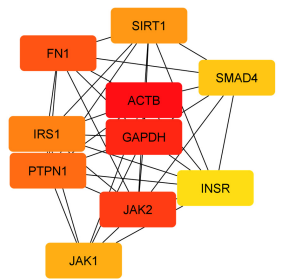

C

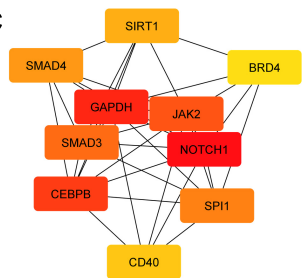

G

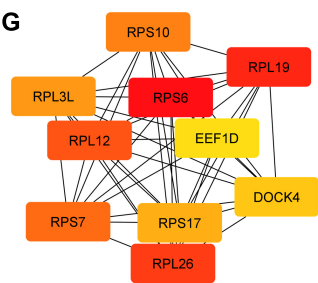

D

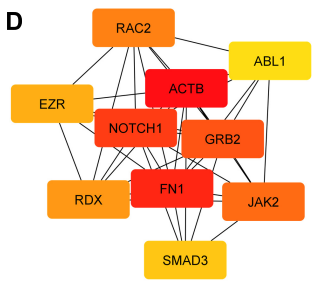

H

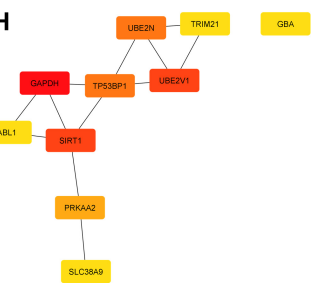

FIGURE 3 | Hub genes in each of the cluster terms identified from the enriched biological functions in the head kidney of Atlantic salmon smolts fed the MPLE supplemented diet. The principal cluster shows the ten-hub genes and the closest neighbor's genes for each network. The color intensity from yellow to red (i.e., yellow, orange, red) represents the degree of the hub gene (i.e., the relevance degree) in each network, being red those most relevant hub genes. (A) Antigen processing and presentation of peptide antigen via MHC class II. (B) Interferon-gamma-mediated signaling pathway. (C) Regulation of I-kappaB kinase/NF-kappaB signaling. (D) Leucocyte activation involved in immune response. (E) Cytoskeleton organization. (F) Regulation of cellular protein metabolic process. (G) Cellular biosynthetic process. (H) Autophagy.

matrix and cytoskeleton) presented a higher expression level in fish fed the MPLE-supplemented diet. Among the structural genes, several components of the extracellular matrix and cytoskeleton organization were upregulated in fish fed the MPLE diet, including genes of the integrin family (itgb4, itgb5, itga10, itga11) and fibronectin ( $f n 1)$. In this context, itgb4, itgb5, itga10 and itga11 were identified as hub genes. Integrins link the extracellular matrix to the cytoskeleton, regulating signal transduction pathways intracellularly (Hynes, 2002). Furthermore, integrins also participate in the immune response (Han et al., 2016). Particularly, the upregulation of $f n 1$,

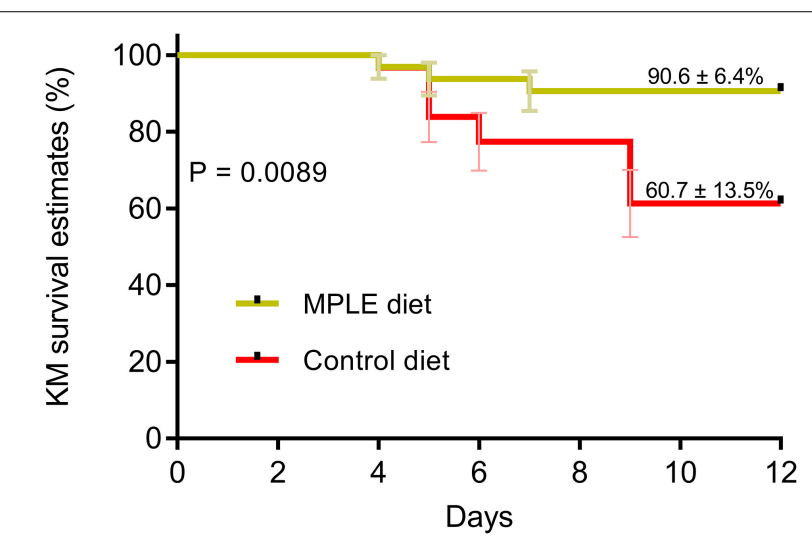

FIGURE 4 | Results of the bacterial challenge conducted in Atlantic salmon

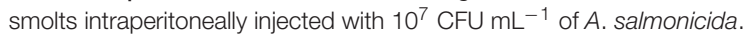
Kaplan-Meier (KM) survival curves (\%) for Atlantic salmon smolts intraperitoneally injected with $A$. salmonicida subsp. salmonicida $\left(10^{7} \mathrm{CFU}\right.$ $\mathrm{mL}^{-1}$ ) during the 12 days challenge trial period. Data correspond to the mean \pm standard error (4 replicates tanks per experimental diet; $n=8$ fish per tank). whose protein product (Fibronectin 1) is an important acute phase protein required for the protection and repair of the extracellular matrix (Jessen, 2015). Even more interesting, it has been shown that there is an interaction between fibronectin and integrins, which may induce cytoskeleton reorganization, focal adhesion formation, and importantly, cell-generated tension to unfold cryptic fibronectin, which is critical for fibronectin matrix assembly (Xu and Mosher, 2011).

\section{Immunomodulatory Effects of the Dietary Medicinal Plant Leaf Extract}

The GO enrichment analysis of all DEGs indicated that the biological processes related to immunity in smolts were significantly modulated by the tested phytogenics in the head kidney, which were consistent with previous results on this additive at systemic and local levels (Salomón et al., 2020, 2021a). This organ undertakes immune functions similarly to the mammalian bone marrow, i.e., hematopoiesis (Tort, 2011). In addition, the head kidney in fish is a basic organ forming blood elements; thus, it is potentially useful for identifying new immune-related genes (Gerdol et al., 2015). The immunomodulatory action at cellular and humoral levels of the tested phytogenic in the head kidney of Atlantic salmon smolts is further discussed as follows.

\section{Antigen Processing and Presentation of Peptide Antigen via MHC Class II}

Diet supplemented with MPLE modulated several biological processes related to immune effector cells in Atlantic salmon smolts. One of them was the cluster "Antigen processing and presentation of peptide antigen via MHC class II (GO:0002495)". Antigen processing and presentation are essential for triggering cellular and humoral immune responses, which are mediated 
by $\mathrm{T}$ and $\mathrm{B}$ lymphocytes (Vyas et al., 2008). Thus, one of the major functions of MHC Class II molecules is presenting antigens derived from extracellular proteins for their recognition by $\mathrm{CD}^{+}$ $\mathrm{T}$ cells, being critical for the initiation of the antigen-specific immune response (Yagamuchi and Dijkstra, 2019). Furthermore, the $\alpha$-and $\beta$-chain of MHC class II molecules are synthesized in the endoplasmic reticulum and associated with the class II invariant chain (also known as CD74) for proper folding, trafficking, and providing protection of the antigen-binding groove (Bryant and Ploegh, 2004). In our study, $c d 74$ was upregulated in fish fed the MPLE-supplemented diet. This gene is a cell-surface receptor for the cytokine known as macrophage migration inhibitory factor (MIF), which plays a specific role as an important component in the functional presentation of MHC class II restricted antigens (Gil-Yarom et al., 2017; Wang et al., 2017). Similar results regarding $c d 74$ expression were observed in virus-challenged Atlantic salmon, results that were correlated to an increased resistance to pancreas disease caused by salmonid alphavirus (Hillestad et al., 2020). In addition, several other genes like hla-dqa1, ctsl, ctsd, kif23, and dync1li2 were upregulated in the cluster associated to this biological process. The major histocompatibility complex, class II, DQ alpha 1 (hla-dqa1), which is one of the MHC Class II family members was one of the upregulated hub genes involved in the above-mentioned cluster. This gene plays a central role helping the immune system to distinguish the host's own proteins from proteins made by viruses and bacteria (Lipton et al., 2011). This is of special relevance since proteins produced by the MHC class II are presented to the immune system, and if the immune system recognizes these peptides as foreign, it triggers a response to attack the invading viruses or bacteria (Mack et al., 1999). Furthermore, other hub genes like those belonging to the cathepsin family were also differentially transcribed between both experimental groups. This family of proteins are known to play important roles in antigen processing and presentation through the MHC II complex, being involved in adaptive immune responses (Conus and Simon, 2010). Under present experimental conditions, two cathepsins ( $c t s d, c t s l)$ were upregulated in smolts fed the phytogenic-supplemented diet. Cathepsin D (ctsd) is a lysosomal endoproteolytic aspartic proteinase that is involved in the presentation of antigenic peptides (Deussing et al., 1998), among other functions (Benes et al., 2008). It has also been shown that deficiency in cathepsin D may cause a delay in the innate immune response during both bacterial infection and septic shock (Cha et al., 2012). Similar to cathepsin D, cathepsin $\mathrm{L}$ is also described to be important in the innate response of teleost, playing key roles in host immune defense via the antigen processing and presentation, through the MHC IIassociated presentation and regulation of $\mathrm{CD} 4^{+} \mathrm{T}$ lymphocyte (Chen et al., 2020). Therefore, our data indicated that the regulation of several genes related to the antigen processing and presentation of peptide antigen via MHC class II pathway suggested that the tested phytogenics might be involved in the regulation of lymphocytes activity trough above-mentioned hub genes; thus, suggesting the stimulation of both innate and adaptive immune responses.

\section{Interferon Gamma Mediated Signaling Pathway and Autophagy}

As it was previously discussed, the dietary administration of MPLE modulated the biological process linked to "Antigen processing and presentation of peptide antigen via MHC class II". Interestingly, interferon gamma (IFN- $\gamma$ ) signaling has been shown to influence the entire process of antigen processing and presentation by inducing MHC class II; thus, contributing to immunity through the enhancement of pathogen-specific $\mathrm{T}$ cell responses (Decker et al., 2005). IFN- $\gamma$ is mainly produced by activated $\mathrm{T}$ cells, natural killer cells, and antigen-presenting cells and it acts on many types of immune cells, regulating both innate and cell-mediated immune responses (Araki et al., 2013). Thus, IFN- $\gamma$ plays critical roles not only in orchestrating both innate and adaptive immune responses against viruses and bacteria, but also in promoting inflammation (Zou and Secombes, 2011). Although, the activities mediated by this molecule are well known in mammals, several aspects of the IFN- $\gamma$ system in teleosts remain a riddle to scientists (Pereiro et al., 2019). Recently, Hu et al. (2021) have demonstrated that the number of IFN- $\gamma$ producing cells increased in rainbow trout challenged with A. salmonicida, results that were associated to an enhanced immune protection. These results may be of particular relevance under the present experimental condition, since Atlantic salmon smolts fed the MPLE diet showed higher survival rates $(90.6 \pm 6.4 \%)$ in comparison to those fed the control diet $(60.7 \pm 13.5 \%)$. Furthermore, another hub gene of relevance found in this biological process is the calcium/calmodulindependent protein kinase II alpha (camk2a). This gene is involved in the production of cytokines such interleukin-6, tumor necrosis factor- $\alpha$ and interferons in macrophages (Liu et al., 2008). In addition, the interaction between two other hub genes such janus kinase 1 (jak1) and janus kinase 2 (jak2) are required for association with the IFN- $\gamma$ receptor chains and downstream signaling. Jak kinase function encompassed components of diverse signal transduction pathways that govern cellular survival, proliferation, differentiation, and apoptosis (Rane and Reddy, 2000; Yamaoka et al., 2004), being involved from disease resistance to maintaining immune tolerance (Villarino et al., 2015).

Another biological process that was modulated by the tested feed additive is "Autophagy" (GO:0006914), which is also modulated by IFN- $\gamma$ (Pereiro et al., 2019). Autophagy is a highly conserved pathway that plays an important role in cellular physiology, adaptive responses to stress, and the immune response (Kuballa et al., 2012). Autophagy as a defense mechanism in teleost in front of intracellular bacterial and viral infections has been well documented (Meijer and van der Vaart, 2014; Pereiro et al., 2017, Yin et al., 2021). In this way, our results showed that "Autophagy (GO:0006914)" was regulated in the head kidney of the Atlantic salmon fed with the functional diet. According to the existing literature, studies have reported that autophagy as well as IFN- $\gamma$ play a specific role against opportunistic pathogens such as Aeromonas spp. in farmed fish (Pereiro et al., 2016; Yin et al., 2021); thus, opening the possibility to understanding and relating our results to the increase in 
disease resistance obtained from the bacterial challenge. For instance, Pereiro et al. (2016) reported a reduction in mortality in turbot (Scophthalmus maximus) when they were challenged with $A$. salmonicida. These results were attributed to the effect of IFN- $\gamma$ in bacterial infections, and the participation of this protein in the inflammatory response (Pereiro et al., 2016). On the other hand, Yin et al. (2021) was able to demonstrate the role of autophagy in grass carp (Ctenopharyngodon idella) monocytes/macrophages, which lead to a promote innate defense against Aeromonas hydrophila.

\section{Regulation of I-kappaB Kinase/NF-kappaB Signaling}

$\mathrm{NF}-\kappa \mathrm{B}$ is an important factor for the maintenance of the immune homeostasis, by modulating the transcription of a diverse group of genes involved in many biological processes such as development, immunity, apoptosis, and cell differentiation in different cell types such as $\mathrm{B}$ and $\mathrm{T}$ cells, monocytes, chemokines, cytokines, among others (Dorrington and Fraser, 2019). In our study, we observed a modulation of the biological process "Regulation of I-kappaB kinase/NF-kappaB signaling (GO:0043122)". This modulation is in line with a recent study from our group, in which we demonstrated that a phytogenic feed additive from the olive fruit (Olea europaea), with biochemical and functional properties similar to MPLE, was also able to modulate biological process such as "Regulation of I-kappaB kinase/NF-kappaB signaling” (Salomón et al., 2021b).

Among the DEGs participating in this GO, the hub gene notch receptor 1 (notch1) is of special relevance. $\mathrm{NOTCH}$ proteins are transmembrane receptors of critical importance for several biological functions (Shin et al., 2014). In particular, notch 1 upregulates the expression of the cytokine IFN- $\gamma$ in $\mathrm{T}$ cells through activation of NF- $\kappa \mathrm{B}$ (Shin et al., 2014), which highlights the connection between NF- $\kappa$ B and IFN- $\gamma$ biological processes. Moreover, we found another hub gene which is involved in the regulation of the NF-кB pathway; in particular, CCAAT enhancer-binding protein beta (cebpb) was upregulated in the head kidney of Atlantic salmon smolts fed the MPLE-supplemented diet. This gene has been well documented in direct association with NF- $\kappa$ B, whose function has been associated to the activation of pro-inflammatory mediators, such as chemokines, being also involved in migration, maturation, and activation of immune cells (Rebl et al., 2014). Last but not least, it has been demonstrated that the hub gene named $c d 40$ and its protein product (TNF receptor superfamily member 5), which is upregulated in our study, has been shown to be capable of stimulating the NF- $\kappa$ B pathway, as well as playing an essential role for the cooperation of $\mathrm{T}$ and B cells in responses to protein antigens (Gong et al., 2009; Hayden and Ghosh, 2014).

\section{Leukocyte Activation Involved in Immune and B Cells Signaling Response}

A successful immune response involves the tight control of a wide repertoire of processes such the leukocyte-mediated cells, among others (Rieger and Barreda, 2011). Leukocyte activation is mediated by several signaling pathways that interact to produce changes in binding protein affinity on the surface of neutrophils that mobilize the cytoskeleton for chemotaxis and phagocytosis, ultimately triggering a respiratory burst and degranulation (Rieger and Barreda, 2011). In our study, the "Leukocyte activation involved in immune response (GO:0002366)" was enriched. In this context, eight of the ten hub genes related to leukocyte activation ( $f n 1$, notch1, grb2, rac2, rdx, ezr, smad3, abl1) were upregulated. Similarly, a modulation of immunerelated GOs such as "Leukocyte activation involved in immune response" were enriched in Atlantic salmon smolts fed a feed additive AQUOLIVE ${ }^{\circledR}$ as we mentioned above from a phytogenic derived from olive (O. europaea) fruit with similar biochemical and functional properties to the MPLE phytogenic tested in the current study (Salomón et al., 2021b). For instance, notch1 a gene we have previously discussed highlighting its connection between NF- $\kappa \mathrm{B}$ and IFN- $\gamma$ as biological processes that have a key role in the differentiation of granulocytes, macrophages, and dendritic cells (Schroeder et al., 2003; Monsalve et al., 2009). This is relevant since, granulocytes, macrophages, dendritic cells, and B cells are recognized as a critical component of the innate and adaptive immunity against pathogens (Secombes and Wang, 2012). These results are in agreement with our transcriptomic data, since biological processes like "Neutrophil mediated immunity (GO:0002446)" and "Lymphocyte activation involved in immune response (GO:0002285)" were also enriched. In addition, we also found the upregulation of rac2 among hub genes. In teleosts, RAC2 (Rac family small GTPase 2) is a member of the Rho family that plays an important role in the host defensemediated neutrophil response, which is a critical first step in innate immunity (Deng et al., 2011; Tell et al., 2012). Moreover, loss of RAC2 activity has been shown to cause severe bacterial infections and deficits in neutrophil function in humans and mice (Tell et al., 2012).

Furthermore, some of these genes involved in the GO "Leukocyte activation involved in immune response" were also associated with the innate and adaptive immunity modulated by the MPLE-supplemented. For instance, fish fed with the MPLE diet showed an increase of the expression in the growth factor receptor bound protein 2 ( $g r b 2)$, which is an essential signal integrator that can interact with multiple genes to regulate signal transduction; thus, playing an important role in regulating B cells activation (Neumann et al., 2009). This is relevant, as $B$ cell activation is essential the development of an effective antigen-specific humoral immune response (Scapigliati et al., 2018). Moreover, two hub genes ( $r d x$, ezr), which are part of the family of proteins called ezrin-radixin-moesin (ERM), were also upregulated in our study. Several studies have demonstrated that ERM proteins are involved in the regulation of $\mathrm{B}$ cell function under healthy and disease conditions (Pore and Gupta, 2015). Therefore, the upregulation of these two genes, $r d x$ and ezr, might confirm the immunomodulatory properties of the MPLE in Atlantic salmon. Therefore, the regulation of genes involved in leukocyte activation and B cells might suggest an increased systemic specific immune capacity promoted by the tested phytogenic feed additive. Thus, our transcriptional analysis seemed to indicate that the tested phytogenic activated leukocytes, which would promote host's disease resistance as the in vivo challenge with a pathogenic bacteria confirmed. 


\section{CONCLUSION}

Phytogenics obtained from sage and lemon verbena included at $0.1 \%$ in diets promoted somatic growth and improved FCR in Atlantic salmon smolts. In addition, data from the microarray analysis of the head kidney samples indicated this feed additive enhanced the host's systemic immune response through the transcriptional regulation of innate immunity processes like leukocytes' activation. We showed that other pathways related to immunity were also enhanced by the tested functional feed additive, such as interferon-gamma-mediated signaling pathway, antigen processing and presentation of peptide antigen via MHC class II, autophagy, and regulation of i-kappaB kinase/NFkappaB, promoting disease resistance when challenged with $A$. salmonicida. Altogether, this study indicated that the tested feed additive promotes systemic immunity and protects Atlantic salmon smolts against bacterial infections like A. salmonicida. According to these findings, we suggest that the combination of current vaccination practices coupled with the administration of MPLE may be a good strategy against furunculosis in salmonids. Furthermore, this phytogenic may be also of interest for other marine species like European sea bass (Dicentrarchus labrax) also suffering from emerging $A$. salmonicida infections in the Mediterranean basin.

\section{DATA AVAILABILITY STATEMENT}

The datasets presented in this study can be found in online repositories. The names of the repository/repositories and accession number(s) can be found in the article/Supplementary Material.

\section{ETHICS STATEMENT}

The animal study was reviewed and approved by Experimental procedures were conducted following the Guiding Principles for Biomedical Research Involving Animals (EU2010/63), the guidelines of the Spanish laws (law 32/2007 and RD 1201/2015)

\section{REFERENCES}

Alipieva, K., Korkina, L., Orhan, I. E., and Georgiev, M. I. (2014). Verbascoside - a review of its occurrence, (bio)synthesis and pharmacological significance. Biotechnol. Adv. 32, 1065-1076. doi: 10.1016/j.biotechadv.2014.07.00

Araki, K., Takizawa, F., Yamasaki, M., Esumi, M., Moritomo, T., Ototake, M., et al. (2013). Expression profiles of interferon gamma genes in response to immunostimulants and alloantigen in ginbuna crucian carp Carassius auratus langsdorfi. Fish. Sci. 79, 213-220. doi: 10.1007/s12562-012-0590-5

Awad, E., and Awaad, A. (2017). Role of medicinal plants on growth performance and immune status in fish. Fish Shellfish Immunol. 67, 40-54. doi: 10.1016/j.fsi. 2017.05.034

Babalola, I. T., and Shode, F. O. (2013). Ubiquitous ursolic acid: a potential pentacyclic triterpene natural product. J. Pharmacogn. Phytochem. 2, 214-222.

Babicki, S., Arndt, D., Marcu, A., Liang, Y., Grant, J. R., Maciejewski, A., et al. (2016). Heatmapper: web-enabled heat mapping for all. Nucleic Acids Res. 44, 147-153. doi: 10.1093/nar/gkw419 and authorized by the Ethical Committee of IRTA (FUE-202001314717).

\section{AUTHOR CONTRIBUTIONS}

EG: conceptualization, resources, project administration, and funding acquisition. MF, EV-V, and FER-L: methodology. RS, FER-L, JF, and EV-V: formal analysis. RS: writing-original draft. MF, EV-V, RS, FER-L, EG, and LT: writing-review and editing. RS, FER-L, and EV-V: visualization. EG and EV-V: supervision. All authors have read and agreed to the published version of the manuscript.

\section{FUNDING}

This work has been financially supported by the project "AQUOLIVE by NATAC, funded by European Union's Horizon 2020 Research and Innovation Program (Grant Agreement No. 830202) and partially by the Agencia Española de Investigación (grant AGL2016-76069-C2-2-R to Universitat Autònoma de Barcelona). FER-L and EV-V thank the support of Fondecyt Regular (No. 1211841) and Fondecyt iniciación grants (No. 11221308), respectively (ANID; Government of Chile). RS was supported by a Ph.D. grant from the government of Paraguay (BECAL). JF has been subsidized by the Industrial Ph.D. program of Generalitat de Catalunya and TECNOVIT-FARMFAES S.L. (No. 2017 DI 017). Collaboration between Ibero-American researchers has been done under the framework of the network LARVAplus "Strategies for the development and improvement of fish larvae production in Ibero-America" (117RT0521) funded by the Ibero-American Program of Science and Technology for Development (CYTED, Spain).

\section{SUPPLEMENTARY MATERIAL}

The Supplementary Material for this article can be found online at: https://www.frontiersin.org/articles/10.3389/fmars. 2022.828497/full\#supplementary-material

Barrett, L. T., Oppedal, F., Robinson, N., and Dempster, T. (2020). Prevention not cure: a review of methods to avoid sea lice infestations in salmon aquaculture. Rev. Aquac. 12, 2527-2543. doi: 10.1111/raq.12456

Beaz-Hidalgo, R., Magi, G. E., Balboa, S., Barja, J. L., and Romalde, J. L. (2008). Development of a PCR protocol for the detection of Aeromonas salmonicida in fish by amplification of the fstA (ferric siderophore receptor) gene. Vet. Microbiol. 128, 386-394. doi: 10.1016/j.vetmic.2007.1 0.004

Benes, P., Vetvicka, V., and Fusek, M. (2008). Cathepsin D-many functions of one aspartic protease. Crit. Rev. Oncol. Hematol. 68, 12-28. doi: 10.1016/j. critrevonc.2008.02.008

Bindea, G., Mlecnik, B., Hackl, H., Charoentong, P., Tosolini, M., Kirilovsky, A., et al. (2009). ClueGO: a Cytoscape plug-in to decipher functionally grouped gene ontology and pathway annotation networks. Bioinformatics 25, 1091-1093. doi: 10.1093/bioinformatics/btp101

Bryant, P., and Ploegh, H. (2004). Class II MHC peptide loading by the professionals. Curr. Opin. Immunol. 16, 96-102. doi: 10.1016/j.coi.2003.11.011 
Caruso, M. A., and Sheridan, M. A. (2011). New insights into the signaling system and function of insulin in fish. Gen. Comp. Endocrinol. 173, 227-247. doi: 10.1016/j.ygcen.2011.06.014

Casamassima, D., Palazzo, M., D‘Alessandro, A. G., Colella, G. E., Vizzarri, F., and Corino, C. (2013). The effects of lemon verbena (Lippia citriodora) verbascoside on the productive performance, plasma oxidative status, and some blood metabolites in suckling lambs. J. Anim. Feed Sci. 22, 204-212. doi: 10.22358/ jafs/65989/2013

Caturla, N., Funes, L., Pérez-Fons, L., and Micol, V. (2011). A randomized, doubleblinded, placebo-controlled study of the effect of a combination of lemon verbena extract and fish oil omega-3 fatty acid on joint management. J. Altern. Comp. Med. 17, 1051-1063. doi: 10.1089/acm.2010.0410

Cha, I. S., Kwon, J., Mun, J. Y., Park, S. B., Jang, H. B., Nho, S. W., et al. (2012). Cathepsins in the kidney of olive flounder, Paralichthys olivaceus, and their responses to bacterial infection. Dev. Comp. Immunol. 38, 538-544. doi: 10. 1016/j.dci.2012.08.00

Chen, J., Zhang, L., Yang, N., Cao, M., Tian, M., Fu, Q., et al. (2020). Characterization of the immune roles of cathepsin L in turbot (Scophthalmus maximus L.) mucosal immunity. Fish Shellfish Immunol. 97, 322-335. doi: 10.1016/j.fsi.2019.12.005

Chin, C. H., Chen, S. H., Wu, H. H., Ho, C. H., Ko, M. T., and Lin, C. Y. (2014). cytoHubba: identifying hub objects and sub-networks from complex interactome. BMC Syst. Biol. 8:S11. doi: 10.1186/1752-0509-8S4-S11

Conus, S., and Simon, H. U. (2010). Cathepsins and their involvement in immune responses. Swiss Med. Wkly. 140:w13042. doi: 10.4414/smw.2010.13042

Corino, C., Rossi, R., Musella, M., Cannata, S., and Pastorelli, G. (2007). Growth performance and oxidative status in piglets supplemented with verbascoside and teupolioside. Ital. J. Anim. Sci. 6, 292-294. doi: 10.4081/ijas.2007.1s.292

Dadras, H., Hayatbakhsh, M. R., and Golpour, A. (2020). Dietary administration of common sage (Salvia officinalis) and coneflower (Echinacea angustifolia) extracts affects growth, blood parameters and immune responses of beluga, Huso huso. Turk. J. Fish. Aquatic Sci. 20, 367-374. doi: 10.4194/1303-2712-v20_ 5_05

Dawood, M. A. O., Koshio, S., and Esteban, M. A. Á. (2018). Beneficial roles of feed additives as immunostimulants in aquaculture: a review. Rev. Aquac. 10, 950-974. doi: 10.1111/raq.12209

Dawood, M. A. O. (2021). Nutritional immunity of fish intestines: important insights for sustainable aquaculture. Rev. Aquac. 13, 642-663. doi: 10.1111/raq. 12492

Decker, T., Müller, M., and Stockinger, S. (2005). The Yin and Yang of type I interferon activity in bacterial infection. Nat. Rev. Immnuol. 5, 675-687. doi: $10.1038 /$ nri1684

Deng, Q., Yoo, S. K., Cavnar, P. J., Green, J. M., and Huttenlocher, A. (2011). Dual roles for Rac2 in neutrophil motility and active retention in zebrafish hematopoietic tissue. Dev. Cell 21, 735-745. doi: 10.1016/j.devcel.2011.07.013

Deussing, J., Roth, W., Saftig, P., Peters, C., Ploegh, H. L., and Villadangos, J. A. (1998). Cathepsins B and D are dispensable for major histocompatibility complex class II-mediated antigen presentation. Proc. Nat. Acad. Sci. U.S.A. 95, 4516-4521. doi: 10.1073/pnas.95.8.4516

Ding, Y. J., Sun, C. H., Wen, C. C., and Chen, Y. H. (2015). Nephroprotective role of resveratrol and ursolic Acid in aristolochic acid intoxicated zebrafish. Toxins 7, 97-109. doi: 10.3390/toxins7010097

Dorrington, M. G., and Fraser, I. D. C. (2019). NF- $\kappa B$ signaling in macrophages: Dynamics, Crosstalk, and Signal Integration. Front. Immunol. 10:705. doi: 10. 3389/fimmu.2019.00705

Elumalai, P., Kurian, A., Lakshmi, S., Faggio, C., Esteban, M. A. Á., and Ringø, E. (2020). Herbal immunomodulators in aquaculture. Rev. Fish. Sci. Aquac. 29, 33-57. doi: 10.1080/23308249.2020.1779651

Encarnação, P. (2016). "Functional feed additives in aquaculture feeds," in Aquafeed Formulation, ed. S. F. Nates (London: Academic Press), 217-237. doi: 10.1016/B978-0-12-800873-7.00005-1

FAO (2021). Fishery and Aquaculture Statistics. Global aquaculture production 1950-2019 (Fishstat). Rome: FAO.

Fernández-Navarro, M., Peragón, J., Esteban, F. J., de la Higuera, M., and Lupiáñez, J. A. (2006). Maslinic acid as a feed additive to stimulate growth and hepatic protein-turnover rates in rainbow trout (Onchorhynchus mykiss). Comp. Biochem. Physiol. 144, 130-140. doi: 10.1016/j.cbpc.2006.07.006
Firmino, J. P., Galindo-Vallegas, J., Reyes-López, F. E., and Gisbert, E. (2021a). Phytogenic bioactive compounds shape fish mucosal immunity. Front. Immunol. 12:695973. doi: 10.3389/fimmu.2021.695973

Firmino, J. P., Vallejos-Vidal, E., Balebona, M. C., Ramayo-Caldas, Y., Cerezo, I. M., Salomón, R., et al. (2021b). Diet, immunity, and microbiota interactions: an integrative analysis of the intestine transcriptional response and microbiota modulation in gilthead seabream (Sparus aurata) fed an essential oils-based functional diet. Front. Immunol. 12:625297. doi: 10.3389/fimmu.2021.625297

Firmino, J. P., Vallejos-Vidal, E., Sarasquete, C., Ortiz-Delgado, J. B., Balasch, J. C., Tort, L., et al. (2020). Unveiling the effect of dietary essential oils supplementation in Sparus aurata gills and its efficiency against the infestation by Sparicotyle chrysophrii. Sci. Rep. 10:17764. doi: 10.1038/s41598-020-74625-5

Fletcher, D. A., and Mullins, D. (2010). Cell mechanics and the cytoskeleton. Nature 463, 485-492. doi: $10.1038 /$ nature 08908

Funes, L., Fernández-Arroyo, S., Laporta, O., Pons, A., Roche, E., and SeguraCarretero, A. (2009). Correlation between plasma antioxidant capacity and verbascoside levels in rats after oral administration of lemon verbena extract. Food Chem. 117, 589-598. doi: 10.1016/j.foodchem.2009.04.059

Gerdol, M., Buonocore, F., Scapigliati, G., and Pallavicini, A. (2015). Analysis and characterization of the head kidney transcriptome from the Antarctic fish Trematomus bernacchii (Teleostea, Notothenioidea): a source for immune relevant genes. Mar. Genomics 20, 13-15. doi: 10.1016/j.margen.2014.12.005

Ghorbani, A., and Esmaeilizadeh, M. (2017). Pharmacological properties of Salvia officinalis and its components. J. Tradit. Comp. Med. 7, 433-440. doi: 10.1016/ j.jtcme.2016.12.014

Gil-Yarom, N., Radomir, L., Sever, L., Kramer, M. P., Lewinsky, H., Bornstein, C., et al. (2017). CD74 is a novel transcription regulator. Proc. Nat. Acad. Sci. U.S.A. 114, 562-567. doi: 10.1073/pnas.1612195114

Gong, Y. F., Xiang, L. X., and Shao, J. Z. (2009). CD154-CD40 interactions are essential for thymus-dependent antibody production in zebrafish: insights into the origin of costimulatory pathway in helper $\mathrm{T}$ cell-regulated adaptive immunity in early vertebrates. J. Immunol. 182, 7749-7762. doi: 10.4049/ jimmunol.0804370

Han, M. M., Lu, J. G., Bin, S., Peng, L. N., Mahboob, S., Al-Ghanim, K. A., et al. (2016). Integrins contributes to innate immune response in Pelteobagrus fulvidraco. Biochem. Physiol. Open Access. 5:2. doi: 10.4172/2168-9652.1000204

Hayden, M. S., and Ghosh, S. (2014). Regulation of NF- $\kappa$ B by TNF family cytokines. Semin. Immunol. 26, 253-266. doi: 10.1016/j.smim.2014.05.004

Hernández-Contreras, Á., and Hernández, M. D. (2020). "Chapter 14 - Application of aromatic plants and their extracts in aquaculture," in Feed Additives, eds P. Florou-Paneri, E. Christaki, and I. Giannenas (London: Academic Press), 239-259. doi: 10.1016/B978-0-12-814700-9.00014-5

Hernández-Sánchez, C., Mansilla, A., de la Rosa, E. J., and de Pablo, F. (2006). Proinsulin in development: new roles for an ancient prohormone. Diabetologia 49, 1142-1150. doi: 10.1007/s00125-006-0232-5

Hillestad, B., Makvandi-Nejad, S., Krasnov, A., and Moghadam, H. K. (2020). Identification of genetic loci associated with higher resistance to pancreas disease (PD) in Atlantic salmon (Salmo salar L.). BMC Genomics 21:388. doi: 10.1186/s12864-020-06788-4

Hu, Y., Alnabulsi, A., Alnabulsi, A., Scott, C., Tafalla, C., Secombes, C. J., et al. (2021). Characterisation and analysis of IFN-gamma producing cells in rainbow trout Oncorhynchus mykiss. Fish Shellfish Immunol. 117, 328-338. doi: 10.1016/ j.fsi.2021.07.022

Hynes, R. O. (2002). Integrins: bidirectional, allosteric signaling machines. Cell 110, 673-687. doi: 10.1016/S0092-8674(02)00971-6

Jessen, J. R. (2015). Recent advances in the study of zebrafish extracellular matrix proteins. Dev. Biol. 401, 110-121. doi: 10.1016/j.ydbio.2014. 12.022

Kaplan, E. L., and Meier, P. (1958). Nonparametric Estimation from Incomplete Observations. J. Am. Stat. Assoc. 53, 457-481. doi: 10.2307/228 1868

Khansari, A. R., Balasch, J. C., Reyes-López, F. E., and Tort, L. (2017). Stressing the inflammatory network: immuno-endocrine responses to allostatic load in fish. Mar. Sci. Res. Technol. 1, 856-862.

Krasnov, A., Timmerhaus, G., Afanasyev, S., and Jørgensen, S. M. (2011). Development and assessment of oligonucleotide microarrays for Atlantic salmon (Salmo salar L.). Comp. Biochem. Physiol. Part D Genomics Proteomics 6, 31-38. doi: 10.1016/j.cbd.2010.04.006 
Kuballa, P., Nolte, W. M., Castoreno, A. B., and Xavier, R. J. (2012). Autophagy and the immune system. Annu. Rev. Immunol. 30, 611-646. doi: 10.1146/annurevimmunol-020711-074948

Kunkel, S. D., Elmore, C. J., Bongers, K. S., Ebert, S. M., Fox, D. K., Dyle, M. C., et al. (2012). Ursolic acid increases skeletal muscle and brown fat and decreases dietinduced obesity, glucose intolerance and fatty liver disease. PLoS One 7:e39332. doi: 10.1371 /journal.pone.0039332

Lagouge, M., Argmann, C., Gerhart-Hines, Z., Meziane, H., Lerin, C., Daussin, F., et al. (2006). Resveratrol improves mitochondrial function and protects against metabolic disease by activating SIRT1 and PGC-1 $\alpha$. Cell 127, 1109-1122. doi: 10.1016/j.cell.2006.11.013

Li, B. Y., Hu, Y., Li, J., Shi, K., Shen, Y. F., Zhu, B., et al. (2019). Ursolic acid from Prunella vulgaris L. efficiently inhibits IHNV infection in vitro and in vivo. Virus Res. 273:197741. doi: 10.1016/j.virusres.2019.19774

Lipton, R. B., Drum, M., Greeley, S. A. W., Danielson, K. K., Bell, G. I., and Hagopian, W. A. (2011). HLA-DQ haplotypes differ by ethnicity in patients with childhood-onset diabetes. Pediatr. Diabetes 12, 388-395. doi: 10.1111/j.13995448.2010.00712.x

Liu, X., Yao, M., Li, N., Wang, C., Zheng, Y., and Cao, X. (2008). CaMKII promotes TLR-triggered proinflammatory cytokine and type I interferon production by directly binding and activating TAK1 and IRF3 in macrophages. Blood 112, 4961-4970. doi: 10.1182/blood-2008-03-144022

Lu, Y., and Foo, L. Y. (2000). Flavonoid and phenolic glycosides from Salvia officinalis. Phytochemistry 55, 263-267. doi: 10.1016/s0031-9422(00)00309-5

Lulijwa, R., Rupia, E. J., and Lfaro, A. C. (2020). Antibiotic use in aquaculture, policies and regulation, health and environmental risks: a review of the top 15 major producers. Rev. Aquac. 12, 640-663. doi: 10.1111/raq.12344

Mack, D. G., Johnson, J. J., Roberts, F., Roberts, C. W., Estes, R. G., David, C., et al. (1999). HLA-class II genes modify outcome of Toxoplasma gondii infection. Int. J. Parasitol. 29, 1351-1358. doi: 10.1016/s0020-7519(99)00152-6

Martino, N. A., Ariu, F., Bebbere, D., Uranio, M. F., Chirico, A., Marzano, G., et al. (2016). Supplementation with nanomolar concentrations of verbascoside during in vitro maturation improves embryo development by protecting the oocyte against oxidative stress: a large animal model study. Reprod. Toxicol. 65 , 204-211. doi: 10.1016/j.reprotox.2016.08.004

Mašterová, I., Uhrín, D., Kettmann, V., and Such $\iota$, V. (1989). Phytochemical study of Salvia officinalis L. Chem. Pap. 43, 797-803.

Meijer, A. H., and van der Vaart, M. (2014). DRAM1 promotes the targeting of mycobacteria to selective autophagy. Autophagy 10, 2389-2391. doi: 10.4161/ 15548627.2014.984280

Miccoli, A., Manni, M., Picchietti, S., and Scapigliati, G. (2021). State-of-the-art vaccine research for aquaculture use: the case of three economically relevant fish species. Vaccines 9:140. doi: 10.3390/vaccines9020140

Milne, J. C., Lambert, P. D., Schenk, S., Carney, D. P., Smith, J. J., Gagne, D. J., et al. (2007). Small molecule activators of SIRT1 as therapeutics for the treatment of type 2 diabetes. Nature 450, 712-716. doi: 10.1038/nature 06261

Monsalve, E., Ruiz-García, A., Baladrón, V., Ruiz-Hidalgo, M. J., Sánchez-Solana, B., Rivero, S., et al. (2009). Notch1 upregulates LPS-induced macrophage activation by increasing NF-kappaB activity. Eur. J. Immunol. 39, 2556-2570. doi: 10.1002/eji.200838722

More, S. J. (2020). European perspectives on efforts to reduce antimicrobial usage in food animal production. Ir. Vet. J. 73:2. doi: 10.1186/s13620-0190154-4

Mosca, M., Ambrosone, L., Semeraro, F., Casamassima, D., Vizzarri, F., and Costagliola, C. (2014). Ocular tissues and fluids oxidative stress in hares fed on verbascoside supplement. Int. J. Food Sci. Nutr. 65, 235-240. doi: 10.3109/ 09637486.2013.836742

Naylor, R. L., Hardy, R. W., Buschmann, A. H., Bush, S. R., Cao, L., Klinger, D. H., et al. (2021). A 20-year retrospective review of global aquaculture. Nature 591, 551-563. doi: 10.1038/s41586-021-03308-6

Neumann, K., Oellerich, T., Urlaub, H., and Wienands, J. (2009). The B-lymphoid Grb2 interaction code. Immunol. Rev. 232, 135-149. doi: 10.1111/j.1600-065X. 2009.00845.x

Pastorelli, G., Rossi, R., and Corino, C. (2012). Influence of Lippia citriodora verbascoside on growth performance, antioxidant status, and serum immunoglobulins content in piglets. Czech J. Anim. Sci. 57, 312-322. doi: 10.17221/6006-CJAS
Pereiro, P., Figueras, A., and Novoa, B. (2019). Insights into teleost interferongamma biology: an update. Fish Shellfish Immunol. 90, 150-164. doi: 10.1016/j. fsi.2019.04.002

Pereiro, P., Forn-Cuni, G., Figueras, A., and Novoa, B. (2016). Pathogendependent role of turbot (Scophthalmus maximus) interferon-gamma. Fish Shellfish Immunol. 59, 25-35. doi: 10.1016/j.fsi.2016.10.021

Pereiro, P., Romero, A., Rosales-Díaz, P., Estepa, A., Figueras, A., and Novoa, B. (2017). Nucleated teleost erythrocytes play an Nk-lysin- and autophagydependent role in antiviral immunity. Front. Immunol. 8:1458. doi: 10.3389/ fimmu.2017.01458

Placha, I., Ryzner, M., Cobanova, K., Faixova, Z., and Faix, S. (2015). Effects of dietary supplementation with sage (Salvia officinalis L.) essential oil on antioxidant status and duodenal wall integrity of laying strain growers. Pol. J. Vet. Sci. 18, 741-749. doi: 10.1515/pjvs-2015-0096

Pore, D., and Gupta, N. (2015). The ezrin-radixin-moesin family of proteins in the regulation of B-cell immune response. Crit. Rev. Immunol. 35, 15-31. doi: 10.1615/CritRevImmunol.2015012327

Quiñones, M., Al-Massadi, O., Fernø, J., and Nogueiras, R. (2014). Cross-talk between SIRT1 and endocrine factors: effects on energy homeostasis. Mol. Cell. Endocrinol. 397, 42-50. doi: 10.1016/j.mce.2014.08.002

Rane, S. G., and Reddy, E. P. (2000). Janus kinases: components of multiple signaling pathways. Oncogene 19, 5662-5679. doi: 10.1038/sj.onc.1203925

Rebl, A., Rebl, H., Korytáø, T., Goldammer, T., and Seyfert, H. M. (2014). The proximal promoter of a novel interleukin-8-encoding gene in rainbow trout (Oncorhynchus mykiss) is strongly induced by CEBPA, but not NF-кB p65. Dev. Comp. Immunol. 46, 155-164. doi: 10.1016/j.dci.2014.0 3.024

Reverter, M., Sarter, S., Caruso, D., Avarre, J. C., Combe, M., Pepey, E., et al. (2020). Aquaculture at the crossroads of global warming and antimicrobial resistance. Nat. Commun. 11:1870. doi: 10.1038/s41467-020-15735-6

Reverter, M., Tapissier-Bontemps, N., Sarter, S., Sasal, P., and Caruso, D. (2021). Moving towards more sustainable aquaculture practices: a meta-analysis on the potential of plant-enriched diets to improve fish growth, immunity and disease resistance. Rev. Aquac. 13, 537-555. doi: 10.1111/raq.12485

Reyes-López, F. E., Ibarz, A., Ordóñez-Grande, B., Vallejos-Vidal, E., Andree, K. B., Balasch, J. C., et al. (2021). Skin Multi-Omics-Based interactome analysis: integrating the tissue and mucus exuded layer for a comprehensive understanding of the teleost mucosa functionality as model of study. Front. Immunol. 11:613824. doi: 10.3389/fimmu.2020.613824

Reyes-López, F. E., Romeo, J. S., Vallejos-Vidal, E., Reyes-Cerpa, S., Sandino, A. M., Tort, L., et al. (2015). Differential immune gene expression profiles in susceptible and resistant full-sibling families of Atlantic salmon (Salmo salar) challenged with infectious pancreatic necrosis virus (IPNV). Dev. Comp. Immunol. 53, 210-221. doi: 10.1016/j.dci.2015.06.017

Rieger, A. M., and Barreda, D. R. (2011). Antimicrobial mechanisms of fish leukocytes. Dev. Comp. Immunol. 35, 1238-1245. doi: 10.1016/j.dci.2011.03.009 Salomón, R., Firmino, J. P., Reyes-López, F. E., Andree, K. B., González-Silvera, D., Esteban, M. A. Á, et al. (2020). The growth promoting and immunomodulatory effects of a medicinal plant leaf extract obtained from Salvia officinalis and Lippia citriodora in gilthead seabream (Sparus aurata). Aquaculture 524:735291. doi: 10.1016/j.aquaculture.2020.735291

Salomón, R., Reyes-López, F. E., Tort, L., Firmino, J. P., Sarasquete, C., OrtizDelgado, J. B., et al. (2021a). Medicinal plant leaf extract from sage and lemon verbena promotes intestinal immunity and barrier function in gilthead seabream (Sparus aurata). Front. Immunol. 12:670279. doi: 10.3389/fimmu. 2021.670279

Salomón, R., Furones, M. D., Reyes-López, F. E., Tort, L., Firmino, J. P., Esteban, M. A. Á., et al. (2021b). A bioactive extract rich in triterpenic acid and polyphenols from Olea europaea promotes systemic immunity and protects Atlantic salmon smolts against furunculosis. Front. Immunol. 12:737601. doi: 10.3389/fimmu.2021.737601

Sánchez-Marzo, N., Lozano-Sánchez, J., de la Luz Cádiz-Gurrea, M., HerranzLópez, M., Micol, V., and Segura-Carretero, A. (2019). Relationships between chemical structure and antioxidant activity of isolated phytocompounds from lemon verbena. Antioxidants 8:324. doi: 10.3390/antiox8080324

Scapigliati, G., Fausto, A. M., and Picchietti, S. (2018). Fish lymphocytes: An evolutionary equivalent of mammalian innate-like lymphocytes? Front. Immunol. 9:971. doi: 10.3389/fimmu.2018.00971 
Schar, D., Klein, E. Y., Laxminarayan, R., Gilbert, M., and Van Boeckel, T. P. (2020). Global trends in antimicrobial use in aquaculture. Sci. Rep. 10:1878. doi: 10.1038/s41598-020-78849-3

Schroeder, T., Kohlhof, H., Rieber, N., and Just, U. (2003). Notch signaling induces multilineage myeloid differentiation and up-regulates PU.1 expression. J. Immunol. 170, 5538-5548. doi: 10.4049/jimmunol.170.11.5538

Secombes, C. J., and Wang, T. (2012). "Chapter 1 - The innate and adaptive immune system of fish," in Infectious Disease in Aquaculture: Prevention and Control, ed. B. Austin (Amsterdam: Elsevier Inc), 3-68.

Shannon, P., Markiel, A., Ozier, O., Baliga, N. S., Wang, J. T., Ramage, D., et al. (2003). Cytoscape: a software environment for integrated models of biomolecular interaction networks. Genome Res. 13, 2498-2504. doi: 10.1101/ gr.1239303

Shin, H. M., Tilahun, M. E., Cho, O. H., Chandiran, K., Kuksin, C. A., Keerthivasan, S., et al. (2014). NOTCH1 can initiate NF-kB activation via cytosolic interactions with components of the $\mathrm{T}$ cell signalosome. Front. Immunol. 5:249. doi: 10.3389/fimmu.2014.00249

Shved, N., Berishvili, G., Mazel, P., Baroiller, J. F., and Eppler, E. (2011). Growth hormone $(\mathrm{GH})$ treatment acts on the endocrine and autocrine/paracrine GH/IGF-axis and on TNF- $\alpha$ expression in bony fish pituitary and immune organs. Fish Shellfish Immunol. 31, 944-952. doi: 10.1016/j.fsi.2011.0 8.012

Simonová, M. P., Chrastinová, L., Mojto, J., Lauková, A., Szabóová, R., and Rafay, J. (2010). Quality of rabbit meat and phyto-additives. Czech J. Food Sci. 28, 161-167. doi: 10.17221/49/2008-CJFS

Sönmez, A. Y., Bilen, S., Alak, G., Hisar, O., Yan $\imath$ k, T., and Biswas, G. (2015). Growth performance and antioxidant enzyme activities in rainbow trout (Oncorhynchus mykiss) juveniles fed diets supplemented with sage, mint and thyme oils. Fish Physiol. Biochem. 41, 165-175. doi: 10.1007/s10695-0140014-9

Stelzer, G., Rosen, N., Plaschkes, I., Zimmerman, S., Twik, M., Fishilevich, S., et al. (2016). The GeneCards suite: from gene data mining to disease genome sequence analyses. Curr. Protoc. Bioinf. 54, 1.30.1-1.30.33. doi: 10.1002/cpbi.5

Stentiford, G. D., Bateman, I. J., Hinchliffe, S. J., Bass, D., Hartnell, R., Santos, E. M., et al. (2020). Sustainable aquaculture through the One Health lens. Nat. Food 1, 468-474. doi: 10.1038/s43016-020-0127-5

Sutili, F. J., Gatlin, D. M. III, Heinzmann, B. M., and Baldisserotto, B. (2018). Plant essential oils as fish diet additives: benefits on fish health and stability in feed. Rev. Aquac. 10, 716-726. doi: 10.1111/raq.12197

Szklarczyk, D., Gable, A. L., Lyon, D., Junge, A., Wyder, S., Huerta-Cepas, J., et al. (2019). STRING v11: protein-protein association networks with increased coverage, supporting functional discovery in genome-wide experimental datasets. Nucleic Acids Res. 47, 607-613. doi: 10.1093/nar/gky1131

Taranger, G. L., Karlsen, Ø., Bannister, R. J., Glover, K. A., Husa, V., Karlsbakk, E., et al. (2015). Risk assessment of the environmental impact of Norwegian Atlantic salmon farming. ICES J. Mar. Sci. 72, 997-1021. doi: 10.1093/icesjms/ fsu 132

Tell, R. M., Kimura, K., and Paliæ, D. (2012). Rac2 expression and its role in neutrophil functions of zebrafish (Danio rerio). Fish Shellfish Immunol. 33, 1086-1094. doi: 10.1016/j.fsi.2012.07.020

Tort, L. (2011). Stress and immune modulation in fish. Dev. Comp. Immunol. 35, 1366-1375. doi: 10.1016/j.dci.2011.07.002

Uniprot (2019). UniProt: a worldwide hub of protein knowledge. Nucleic Acids Res. 47, 506-515. doi: 10.1093/nar/gky1049

Vallejos-Vidal, E., Reyes-López, F. E., Teles, M., and MacKenzie, S. (2016). The response of fish to immunostimulant diets. Fish Shellfish Immunol. 56, 34-69. doi: 10.1016/j.fsi.2016.06.028

Vaseeharan, B., and Thaya, R. (2014). Medicinal plant derivatives as immunostimulants: an alternative to chemotherapeutics and antibiotics in aquaculture. Aquac. Int. 22, 1079-1091. doi: 10.1007/s10499-013-9 729-3

Villarino, A. V., Kanno, Y., Ferdinand, J. R., and O’Shea, J. J. (2015). Mechanisms of Jak/STAT signaling in immunity and disease. J. Immunol. 194, 21-27. doi: 10.4049/jimmunol.1401867

Vincken, J. P., Heng, L., de Groot, A., and Gruppen, H. (2007). Saponins, classification and occurrence in the plant kingdom. Phytochemistry 68, 275-297. doi: $10.1016 /$ j.phytochem.2006.10.008

Vyas, J. M., Van der Veen, A. G., and Ploegh, H. L. (2008). The known unknowns of antigen processing and presentation. Nat. Rev. Immunol. 8, 607-618. doi: $10.1038 /$ nri2368

Waagbø, R., and Remø, S. C. (2020). "Functional diets in fish health management," in Aquaculture Health Management, eds F. S. B. Kibenge and M. D. Powell (London: Academic Press), 187-234. doi: 10.1016/B978-0-12-813359-0. 00007-5

Wang, M., Shao, Y., Li, J., Zhu, N., Rangarajan, M., LaVoie, A. J., et al. (1999). Antioxidative phenolic glycosides from sage (Salvia officinalis). J. Nat. Prod. 62, 454-456. doi: 10.1021/np980436g

Wang, Z. Q., Milne, K., Webb, J. R., and Watson, P. H. (2017). CD74 and intratumoral immune response in breast cancer. Oncotarget 8, 12664-12674. doi: 10.18632 /oncotarget.8610

Woźniak, L., Skąpska, S., and Marszałek, K. (2015). Ursolic acid-a pentacyclic triterpenoid with a wide spectrum of pharmacological activities. Molecules 20, 20614-20641. doi: 10.3390/molecules201119721

Xu, J., and Mosher, D. (2011). "Fibronectin and other adhesive glycoproteins," in The Extracellular Matrix: An Overview, ed. R. P. Mecham (Berlin: Springer), 41-75. doi: 10.1007/978-3-642-16555-9_2

Yagamuchi, T., and Dijkstra, J. M. (2019). Major histocompatibility complex (MHC) genes and disease resistance in fish. Cells 8:378. doi: 10.3390/ cells 8040378

Yamaoka, K., Saharinen, P., Pesu, M., Holt, V. E. III, Silvennoinen, O., and O’Shea, J. J. (2004). The Janus kinases (Jaks). Genome Biol. 5:253. doi: 10.1186/gb-20045-12-253

Yin, L., Xu, W., Liu, X., Wang, Y., Ge, P., Wang, X., et al. (2021). Autophagy promotes innate defense against Aeromonas hydrophila in grass carp (Ctenopharyngodon idella) monocytes/macrophages. Aquaculture 535:736391. doi: 10.1016/j.aquaculture.2021.736391

Zou, J., and Secombes, C. J. (2011). Teleost fish interferons and their role in immunity. Dev. Comp. Immunol. 35, 1376-1387. doi: 10.1016/j.dci.2011.07.001

Conflict of Interest: JQ and JP-R are current NATAC BIOTECH S.L. employers.

The remaining authors declare that the research was conducted in the absence of any commercial or financial relationships that could be construed as a potential conflict of interest.

Publisher's Note: All claims expressed in this article are solely those of the authors and do not necessarily represent those of their affiliated organizations, or those of the publisher, the editors and the reviewers. Any product that may be evaluated in this article, or claim that may be made by its manufacturer, is not guaranteed or endorsed by the publisher.

Copyright (C) 2022 Salomón, Furones, Reyes-López, Tort, Firmino, Quintela, PinillaRosas, Vallejos-Vidal and Gisbert. This is an open-access article distributed under the terms of the Creative Commons Attribution License (CC BY). The use, distribution or reproduction in other forums is permitted, provided the original author(s) and the copyright owner(s) are credited and that the original publication in this journal is cited, in accordance with accepted academic practice. No use, distribution or reproduction is permitted which does not comply with these terms. 